\title{
Reactive Astrogliosis Causes the Development of Spontaneous Seizures
}

\author{
Stefanie Robel, ${ }^{1}$ Susan C. Buckingham, ${ }^{1}$ OJessica L. Boni, ${ }^{1}$ Susan L. Campbell, ${ }^{1}$ Niels C. Danbolt, ${ }^{2}$ \\ Therese Riedemann, ${ }^{3}$ Bernd Sutor, ${ }^{3}$ and Harald Sontheimer ${ }^{1}$ \\ ${ }^{1}$ Department of Neurobiology, Center for Glial Biology in Medicine, University of Alabama at Birmingham, Birmingham, Alabama 35209, ${ }^{2}$ Department of \\ Anatomy, Institute of Basic Medical Sciences, University of Oslo, 0317 Oslo, Norway, and ${ }^{3}$ Institute of Physiology, Department of Physiological Genomics, \\ Ludwig-Maximilians-University of Munich, 80336 Munich, Germany
}

Epilepsy is one of the most common chronic neurologic diseases, yet approximately one-third of affected patients do not respond to anticonvulsive drugs that target neurons or neuronal circuits. Reactive astrocytes are commonly found in putative epileptic foci and have been hypothesized to be disease contributors because they lose essential homeostatic capabilities. However, since brain pathology induces astrocytes to become reactive, it is difficult to distinguish whether astrogliosis is a cause or a consequence of epileptogenesis. We now present a mouse model of genetically induced, widespread chronic astrogliosis after conditional deletion of $\beta 1$-integrin (Itg $\beta 1$ ). In these mice, astrogliosis occurs in the absence of other pathologies and without BBB breach or significant inflammation. Electroencephalography with simultaneous video recording revealed that these mice develop spontaneous seizures during the first six postnatal weeks of life and brain slices show neuronal hyperexcitability. This was not observed in mice with neuronal-targeted $\beta 1$-integrin deletion, supporting the hypothesis that astrogliosis is sufficient to induce epileptic seizures. Whole-cell patch-clamp recordings from astrocytes further suggest that the heightened excitability was associated with impaired astrocytic glutamate uptake. Moreover, the relative expression of the cation-chloride cotransporters (CCC) NKCC1 (Slc12a2) and KCC2 (Slc12a5), which are responsible for establishing the neuronal $\mathrm{Cl}^{-}$gradient that governs GABAergic inhibition were altered and the NKCC1 inhibitor bumetanide eliminated seizures in a subgroup of mice. These data suggest that a shift in the relative expression of neuronal NKCC1 and KCC2, similar to that observed in immature neurons during development, may contribute to astrogliosis-associated seizures.

Key words: astrocytes; astrogliosis; bumetanide; EEG; epilepsy; seizures

\section{Introduction}

Epilepsy is the most prevalent chronic brain disorder (Thurman et al., 2011) characterized by repetitive, spontaneous seizures. Seizures are clinical manifestations of hypersynchronous neuronal activity originating at restricted sites of the brain. From these epileptogenic foci, the activity can spread to larger portions of the cerebral cortex resulting in neuronal network hyperexcitability caused by an imbalance between synaptic excitation and synaptic inhibition (Jefferys, 1990; Pinto et al., 2005; Trevelyan et al., 2006; Carmignoto and Haydon, 2012). Almost all available therapeutic

Received April 17, 2014; revised Dec. 16, 2014; accepted Jan. 12, 2015.

Author contributions: S.R., S.C.B., S.L.C., and H.S. designed research; S.R., S.C.B., J.L.B., S.L.C., T.R., and B.S performed research; N.C.D. contributed unpublished reagents/analytic tools; S.R., S.C.B., J.L.B., S.L.C., T.R., and B.S. analyzed data; S.R. and B.S. wrote the paper.

This work was supported by National Institutes of Health (NIH) grants 2R01NS036692, 5R01NS031234, 5R01NS052634, 1F31NS074597, and 1R01NS082851. S.R. received funding from the German Research Foundation, the Epilepsy Foundation, and the American Brain Tumor Association. S.C.B. directs the EEG Core funded by National Institutes of Health Eunice Kennedy Shriver Intellectual and Developmental Disabilities \#5P30HD038985. We thank Briana D. Miller and Miki Jinno for assistance with the mouse colony and for technical support. We are grateful to Leda Dimou for supplying $\beta 1$-integrin, Nex::Cre mice.

The authors declare no competing financial interests.

Correspondence should be addressed to Stefanie Robel, 1719 6th Avenue South, CIRC 252C, Birmingham, AL 35294. E-mail: srobel@uab.edu.

DOI:10.1523/JNEUROSCI.1574-14.2015

Copyright $\odot 2015$ the authors $\quad 0270-6474 / 15 / 353330-16 \$ 15.00 / 0$ anticonvulsants either act on synaptic mechanisms to restore the balance between excitation and inhibition or on voltage-dependent ion channels to reduce neuronal excitability. However, approximately one-third of the patients affected suffer from therapyresistant epilepsies (Wahab et al., 2010). It seems to be a legitimate assumption that disturbances of synaptic mechanisms and/or changes in neuronal excitability are epiphenomena of other possibly more severe dysfunctions. Therefore, a better understanding of the underlying mechanisms leading to epileptic seizures is essential.

It is now widely acknowledged that most neuropathologies involve both neuronal and glial cell dysfunction. Astrocytes have critical roles in the healthy brain, including the maintenance of ion and neurotransmitter homeostasis (Volterra and Meldolesi, 2005). Changes in astrocyte morphology, biochemistry, and physiology in response to CNS insults are collectively termed "reactive astrogliosis" (Sofroniew and Vinters, 2010).

Astrogliosis is also thought to contribute to the epilepsy disease phenomenon (Olsen and Sontheimer, 2008; Wetherington et al., 2008; Seifert et al., 2010). In animal models, reactive astrocytes undergo extensive physiological changes that alter ion and neurotransmitter homeostasis, and intracellular and extracellular water content, which can cause neuronal hyperexcitability (Bordey and Sontheimer, 1998; Bordey et al., 2001; Seifert and Steinhauser, 2011). 
Does astrogliosis precede neuronal network hyperexcitability, or does astrogliosis result from seizures and then exacerbate hyperexcitability? Ortinski et al. (2010) investigated the role of astrogliosis in the development of hyperexcitability after adenoviral infection of hippocampal astrocytes. This led to downregulation of the astrocytic enzyme glutamine synthetase, which transforms glutamate into glutamine. Loss of this enzyme impaired the excitation/inhibition balance of network activity within the hippocampus, leading to neuronal hyperexcitability in acute slices.

In our study, we investigated whether reactive astrogliosis causes epileptic seizures in vivo. For this purpose, we conditionally deleted $\beta 1$-integrin $(\operatorname{Itg} \beta 1)$ in radial glia, which results in chronic reactive astrogliosis in almost every region of the brain without gross brain abnormalities or pronounced inflammation (Robel et al., 2009). We show that these animals develop neuronal hyperexcitability and spontaneous recurrent seizures. This might be attributable in part to reduced expression of the chloride transporter $\mathrm{KCC} 2$, which counteracts neuronal chloride import of NKCC1. Balanced expression of NKCC1 and KCC2 are crucial for the proper function of the inhibitory neurotransmitter GABA. Inhibition of NKCC1 with bumetanide rescued the seizure phenotype in a subset of mice. Patch-clamp recordings in acute brain slices show reduced astrocytic Kir currents and impaired glutamate homeostasis, which together may provide an enhanced excitatory drive. Importantly, neuronal hyperexcitability was not observed in mice with neuron-specific $\beta 1$-integrin deletion. Thus, genetically induced astrogliosis is sufficient to invoke neuronal changes that produce hyperexcitability and epileptic seizures, albeit the mechanism whereby astrogliosis causes these neuronal changes is not known.

\section{Materials and Methods}

Animals. FVB-N//129/Sv- $\beta 1$-integrin mice carrying alleles for $\operatorname{Itg} \beta 1$ flanked by loxP sites $\beta 1$-integrin ${ }^{\mathrm{fl} / \mathrm{fl}}$ (Potocnik et al., 2000) were mated to mice expressing a Cre-recombinase under the hGFAP promoter (hGFAP-Cre ${ }^{+}$) (FVB-Tg (GFAP-cre) 25Mes/J; The Jackson Laboratory, strain \#004600) to recombine in astrocytes and neurons (Zhuo et al., 2001), or in neurons only when expressed under the Nex promoter (Nex::Cre ${ }^{+/-}$; Goebbels et al., 2006). To genetically label astrocytes, FVB-N//Swiss Webster-Aldh1l1-eGFP mice (Cahoy et al., 2008) were mated to the $\beta 1$-integrin//hGFAP-Cre mouse line. Offspring was used after three generations of backcrossing $\beta 1$-integrin//hGFAP-Cre mice to FVB/NJ mice (The Jackson Laboratory; strain \#001800). Mice of either sex were included in the analysis. All animal procedures were approved and performed according to the guidelines of the Institutional Animal Care and Use Committee of the University of Alabama at Birmingham and in accordance with the policies on the Use of Animals and Humans in Neuroscience Research, revised and approved by the Society of Neuroscience.

EEG acquisition. Intracranial recording electrodes (Plastics One) were inserted through the cranium over each hemisphere, with a reference electrode placed over the left. Stainless steel screws (Small Parts) were anchored into the skull to provide stability for the dental acrylic, applied to cover the electrodes and the screws. The scalp incision was then closed with skin glue. Animals were allowed to recover for $5 \mathrm{~d}$ before EEG recording. For wired EEG recordings, animals were housed individually in eight specially constructed cages, each fitted with an amplifier (BIOPAC Systems) and a varifocal IR digital camera (Digimerge Technology). EEG data were collected at a sampling rate of $500 \mathrm{~Hz}$. Data were acquired, digitized, and analyzed off-line using AcqKnowledge 4.1 Software (BIOPAC Systems). EEG data analysis, including duration, amplitude, and frequency of abnormal EEG events, was conducted by an investigator blinded to genotype and treatment groups. None of the analyses was automated. Seizure data were collected from all of the data sampled. For animals with high interictal spiking frequencies, e.g., the $>6$ months of age group, several $1 \mathrm{~h}$ time frames were chosen randomly from the entire recording. Time frames with noise distorting the EEG signal frequently were excluded from the analysis of interictal spiking. Corresponding video recordings (L20WD800 Series; Lorex Technology), aligned temporally with EEG acquisition, were used to assess animal behavior during abnormal EEG activity.

Whole-cell patch-clamp recordings. Animals were decapitated and the brains removed and immersed in ice-cold cutting solution containing the following (in mM): $135 \mathrm{~N}$-methyl-D-gluconate, $1.5 \mathrm{KCl}, 1.5 \mathrm{KH}_{2} \mathrm{PO}_{4}$, 23 choline bicarbonate, $25 \mathrm{D}$-glucose, $0.5 \mathrm{CaCl}_{2}$, and $3.5 \mathrm{MgSO}_{4}$. Coronal slices $(300 \mu \mathrm{m})$ recovered $1 \mathrm{~h}$ in normal recording solution contained the following (in mM): $125 \mathrm{NaCl}, 3 \mathrm{KCl}, 1.25 \mathrm{NaH}_{2} \mathrm{PO}_{4}, 25 \mathrm{NaHCO}_{3}, 2$ $\mathrm{CaCl}_{2}, 1.3$ or $2 \mathrm{MgSO}_{4}$, and $25 \mathrm{D}$-glucose at $28^{\circ} \mathrm{C}$ and $1 \mathrm{~h}$ at room temperature before recording. Whole-cell patch-clamp recordings were obtained using an intracellular solution consisting of the following (in $\mathrm{mM}$ ): $134 \mathrm{~K}$-gluconate, $1 \mathrm{KCl}, 10 \mathrm{HEPES}, 2 \mathrm{Mg}$-ATP, $0.2 \mathrm{Na}$-GTP, and 0.5 EGTA, pH 7.4, 285-290 mOsm. Tight seals were established using patch electrodes (KG-33 glass; Garner Glass) with a 3-8 M $\Omega$ open-pipette resistance at $-70 \mathrm{mV}$ for pyramidal neurons and $-80 \mathrm{mV}$ for astrocytes as previously described (Olsen et al., 2006). Layer II/III pyramidal cells and astrocytes were visualized using a Zeiss Axio Scope microscope, a $40 \times$ water-immersion objective, and infrared or, alternatively in addition, epifluorescent illumination (GFP-positive astrocytes in Aldh1l1eGFP mice). Drugs were added to the recording solution (50 $\mu \mathrm{M}$ D-AP5, 500 nм TTX, $0.1 \mathrm{~mm} \mathrm{CdCl}_{2}$ (Sigma), $0.1 \mathrm{~mm} \mathrm{BaCl}_{2}$ (Sigma), $20 \mu \mathrm{M}$ bicuculline methiodide, $0.3 \mathrm{~mm}$ DL-threo- $\beta$-benzyloxyaspartic acid (TBOA), and $0.4 \mathrm{~mm}$ dihydrokainic acid (DHK). Unless stated otherwise, all drugs were purchased from Tocris Bioscience. Data were acquired using Clampex 10 software and a 19 Digidata 1440A interface (Molecular Devices), filtered at $5 \mathrm{kHz}$, digitized at $10-20 \mathrm{kHz}$, and analyzed using Clampfit 10.0 software (Molecular Devices). Resting membrane potentials (RMPs; in $I=0$ mode), whole-cell capacitance, and series resistances were measured directly from the amplifier, $\sim 1 \mathrm{~min}$ after whole-cell access was obtained. Series resistance compensation was adjusted to $85 \%$ to reduce voltage errors. Slices were continuously perfused with ACSF at $32^{\circ} \mathrm{C}$.

Pressure application of potassium or glutamate was performed using the Pico-liter Injector PLI-10 (Warner Instruments) at an injection pressure of 2 psi for $50 \mathrm{~ms}$ ( $\mathrm{K}^{+}$uptake) or $500 \mathrm{~ms}$ (glutamate uptake). Uptake was recorded three times for each cell and condition. Traces were averaged before analysis.

Neocortical layer II/III pyramidal neurons from $\beta 1$-integrin ${ }^{\mathrm{f} / \mathrm{fl} l}$, Nex::Cre ${ }^{+/-}$and $\beta 1$-integrin ${ }^{\mathrm{f} / \mathrm{wt}}$, Nex::Cre ${ }^{+/-}$mice were recorded using a switched current- and voltage-clamp amplifier (SEC $10 \mathrm{~L}$; npi). Recordings were performed using either the current-clamp mode or the switched voltage-clamp mode at a switching frequency of $\sim 42 \mathrm{kHz}$ (duty cycle $25 \%$ ). Initially, the membrane potential and current-voltage relationship of the neurons was assessed in the current-clamp mode. Further recordings were made in voltage-clamp mode at a holding potential of $-70 \mathrm{mV}$. Following a $10 \mathrm{~min}$ baseline recording, the normal recording solution was replaced by an $\mathrm{Mg}^{2+}$-free solution. In some cases D-AP5 (10 $\mu \mathrm{M})$ or bicuculline methiodide $(10 \mu \mathrm{M})$ was added to the $\mathrm{Mg}^{2+}$-free bathing solution. Occasionally, neurons were recorded in current-clamp mode following $\mathrm{Mg}^{2+}$ withdrawal. The recorded signals were filtered at $10 \mathrm{kHz}$ (current-clamp mode) or $5 \mathrm{kHz}$ (voltage-clamp mode). For offline analysis, the signals were sampled at a rate of $5-10 \mathrm{kHz}$ using a computer equipped with an analog/digital-converter (PCI-6024E; National Instruments). Sampling and data storage were controlled using the program CellWorks (npi). Data were analyzed using IGOR Pro software (WaveMetrics).

Histological procedures. Adult animals were deeply anesthetized with ketamine/xylazine and transcardially perfused with PBS followed by $4 \%$ PFA (Santa Cruz Biotechnology; $50 \mathrm{ml} /$ animal). Brains were postfixed in the same fixative for $12 \mathrm{~h}$ at $4^{\circ} \mathrm{C}$, washed in PBS, and embedded in $4 \%$ agarose for cutting $50-100 \mu \mathrm{m}$ vibratome sections. For immunofluorescent labeling, sections were incubated overnight at $4^{\circ} \mathrm{C}$ in PBS containing the first antibody, $0.5 \%$ Triton X-100 (TX), and 10\% NGS, then washed in PBS and incubated for $1 \mathrm{~h}$ at room temperature (RT) in $0.5 \% \mathrm{TX}$ and $10 \%$ NGS containing the secondary antibody raised against mouse IgG or rabbit generated in goat and coupled to either Alexa 488, Alexa 550, or 
Alexa 647 (Jackson ImmunoResearch). Primary antibodies used included mouse anti-GFAP (Millipore; 1:1000), rabbit anti-GFAP (Dako, \#Z0334; 1:1000), chicken anti-GFAP (Millipore; 1:1000), rat anti-Cd11b (AbD; Serotec, \#MCA711; 1:500), rabbit anti-Kir4.1 (Alomone, \#APC035; 1:500), rabbit anti-glutamine synthetase (Abcam, \#ab16802; 1:500), rabbit anti-Glt-1 (anti-B12, rat Glt-1 residues 12-26; batch number "ab\#360," $0.2 \mathrm{mg} / \mathrm{ml}$; 1:1000; Holmseth et al., 2005). After washing in PBS, sections were mounted on glass slides, embedded in Aqua-Poly/ Mount, and covered by a glass coverslip.

Quantification was performed using Fiji/ImageJ in confocal images of six different regions of interest within the cortical gray matter from three different slices representing different planes along the anterior-posterior axis of the forebrain and spanning all six cortical layers. After collapsing the hyperstacks, binary images were made and the area occupied by GFAP immunohistochemistry was measured.

Western blotting. Anesthetized animals were decapitated and the cortical gray matter was dissected in ice-cold HBSS containing $10 \mathrm{~mm}$ HEPES. Tissue was flash frozen on dry ice and stored at $-80^{\circ} \mathrm{C}$ until tissue lysis was performed. RIPA buffer (containing $50 \mathrm{~mm}$ Tris $\mathrm{HCl}, \mathrm{pH}$ $7.5,150 \mathrm{~mm} \mathrm{NaCl}, 1 \% \mathrm{NP}-40,0.5 \%$ sodium deoxycholate, and 1\% SDS) was supplemented with protease (Sigma) and phosphatase inhibitor (Sigma). This lysis buffer was added to the tissue samples and the tissue homogenized using a Dounce tissue grinder (Wheaton). After sonication, homogenates were centrifuged for $5 \mathrm{~min}$ at $12,000 \times g$ at $4^{\circ} \mathrm{C}$. Protein quantification was performed on the supernatant using a Lowry protein assay kit (Bio-Rad) or a BCA protein assay kit (Thermo Scientific). Laemmli-SDS sample buffer, containing $600 \mathrm{~mm} \beta$-mercaptoethanol, was added to the protein samples before incubating them at $60^{\circ} \mathrm{C}$ for $15 \mathrm{~min}$ or at $95^{\circ} \mathrm{C}$ for $10 \mathrm{~min}$. Fifteen to twenty-five micrograms of protein were loaded into each lane of a $4-15 \%$ gradient precast acrylamide SDS-PAGE gel (BioRad). Samples were separated at 100-200 V. Protein was transferred onto $0.45 \mu \mathrm{m}$ PVDF Transfer membranes (Thermo Scientific; \#88518) in Mini Trans-Blot Electrophoretic Transfer Cells (Bio-Rad) at $100 \mathrm{~V}$ for 1 h. Membranes were blocked in TBST ( $0.1 \%$ Tween 20 in TBS) containing $10 \%$ nonfat dried milk for $30 \mathrm{~min}$ at room temperature or at $4^{\circ} \mathrm{C}$ overnight. Blots were incubated in primary antibody solution (TBST, $10 \%$ goat serum and antibody) for $2 \mathrm{~h}$ at room temperature or at $4^{\circ} \mathrm{C}$ overnight. Blots were washed in TBST $3 \times$ for $10 \mathrm{~min}$ and incubated in secondary anti-rabbit, anti-mouse, or anti-sheep horseradish peroxidase-conjugated antibody 1:1500 (Santa Cruz Biotechnology) for $1 \mathrm{~h}$ at room temperature. Membranes were washed in TBST $3 \times$ for $10 \mathrm{~min}$ and developed using Luminol (Santa Cruz Biotechnology) or Femto (Thermo Scientific) chemiluminescence kits, and chemiluminescence was detected using a 4000 MM Kodak imaging station and Kodak molecular imaging software v.4.0.4. Primary antibodies included mouse anti-GAPDH (Abcam, \#ab9483; 1:5000), sheep anti-GLAST (anti A1, rat GLAST residues 1-25, batch \#ab286; $1.2 \mathrm{mg} / \mathrm{ml} ; 1$ :6000; Li et al., 2012), rabbit anti-Glt-1 (anti-B12, rat Glt-1 residues 12-26, batch \#ab360; 0.2 $\mathrm{mg} / \mathrm{ml}$; 1:3500; Holmseth et al., 2005), rabbit anti-Kir4.1 (Alomone Labs, \#APC-035; 1:2500), and rabbit anti-GFAP (Dako, \#Z00334; 1:10,000).

Statistical analysis. Statistics were computed, generated, and graphed with GraphPad Prism 5 or 6 (GraphPad Software). The significance level was set to $p<0.05$. Data were tested for normal distribution using the Kolmogorov-Smirnov normality test. Statistical tests were chosen accordingly and are specified in the results. Unless stated otherwise, all values are reported as mean \pm SEM, with $n$ being the number of animals or cells sampled, as detailed in Results. Box-and-whisker plots display minimum to maximum values, and mean is shown as "+". Biophysical recordings were plotted using Origin 8 (MicroCal) or IGOR Pro 6 (WaveMetrics). Statistical significance with ${ }^{\star} p<0.05,{ }^{* *} p<0.01$, and ${ }^{* * *} p<0.001$.

\section{Results}

\section{Conditional deletion of $\beta 1$-integrin causes progressive reactive astrogliosis}

Loss of $\beta 1$-integrins in radial glial progeny during the first postnatal week leads to widespread reactive astrogliosis in adult mice without causing abnormal cortical layering, cell death, or opening of the blood-brain barrier (Robel et al., 2009).

We previously showed a relatively slow turnover of $\beta 1$ integrins after Cre-mediated recombination $\sim$ E13. Decreased protein levels were first observed at $\mathrm{P} 0$ and were further decreased 1 week after birth (Robel et al., 2009). In the prior study we addressed the consequences of loss of $\beta 1$-integrins exclusively in adult mice. Here, we set out to determine the phenotype onset. We collected cortical gray matter tissue from $\beta 1^{-1-}$ and control mice at different ages for immunohistochemical and Western blot analysis. While GFAP is expressed by radial glia late during embryonic development in the healthy mouse brain, this intermediate filament is downregulated in most astrocytes of the cortical gray matter during the first 2 weeks after birth (Cahoy et al., 2008). Accordingly, control $\left(\beta 1\right.$-integrin ${ }^{w / w}$, hGFAP-Cre ${ }^{+} ; \beta 1-$ integrin $^{\mathrm{f} / \mathrm{fl}}$, hGFAP-Cre-; $\beta 1$-integrin ${ }^{\mathrm{f} / \mathrm{wt}}$, hGFAP-Cre ${ }^{-}$) and $\beta 1$-integrin ${ }^{\text {fl/fl }}$, hGFAP-Cre ${ }^{+}\left(\beta 1^{-/-}\right)$brains had similarly low numbers of $\mathrm{GFAP}^{+}$astrocytes at 2 weeks of age (Fig. 1a). However, at 4 weeks, GFAP was upregulated in $\beta 1^{-1-}$ brains compared with littermate controls. GFAP + astrocytes were found mainly in layer I/II and V/VI at 4 weeks, whereas at 6 weeks, almost all cortical gray matter astrocytes showed increased GFAP expression (Fig. 1a; Robel et al., 2009). Western blot analysis of cortical gray matter tissue confirmed significantly higher GFAP protein levels between control and $\beta 1^{-1-}$ cortical gray matter at 4 and 6 weeks, and in tissue of animals older than 6 months (Fig. $1 b)$. Note that the quantification of the GFAP immunohistochemistry (Fig. 1a) represents the area occupied by GFAP ${ }^{+}$cells rather than protein expression levels (Fig. 1b).

Astrocytic hypertrophy increased concomitantly with GFAP levels (Fig. 1a, higher power images). We showed previously that, in addition, characteristic antibody markers for immature astrocyte-like stem cells, such as vimentin and tenascin-C, are upregulated. However, in these animals, astrocytes do not undergo proliferation in vivo or in vitro and astrocyte densities are unchanged (Robel et al., 2009).

We previously observed mild microglia activation in adult mice that was unassociated with significantly increased microglia numbers or proliferation (Robel et al., 2009). Immunohistochemistry done in $\beta 1^{-/-}$mice at younger ages revealed mild microglial activation, including increased $\mathrm{Cd} 11 \mathrm{~b}$ expression and a deramified phenotype starting at $\geq 6$ weeks of age (Fig. 1c). Interestingly, no morphological changes or difference in $\mathrm{Cd} 11 \mathrm{~b}$ immunohistochemistry were observed at 4 weeks of age. Thus $\mathrm{Cd} 11 \mathrm{~b}^{+}$reactive microglia appear later than GFAP+ reactive astrocytes, suggesting that microglia are activated as a consequence of astrocyte activation (see also (Robel et al., 2009).

Together, $\beta 1^{-I-}$ mice display a progressive astrogliosis phenotype with late postnatal onset and mild microgliosis secondary to astrocyte activation.

\section{Mice with chronic astrogliosis develop spontaneous seizures}

Epileptic foci are known to contain reactive astrocytes (D'Ambrosio, 2004; Wetherington et al., 2008; Carmignoto and Haydon, 2012; Coulter and Eid, 2012), yet whether they are a consequence of neuronal dysfunction or an active contributor is currently unknown (Verkhratsky et al., 2012). Since hippocampal neuronal hyperexcitability had been observed following adenoviral-induced astrogliosis (Ortinski et al., 2010), we sought to investigate whether the widespread astrogliosis in $\beta 1^{-1-}$ mice leads to spontaneous seizure development.

To assess gross cortical activity, we recorded subcranial cortical EEGs from different age groups of $\beta 1^{-/-}$mice and controls. 
a Control
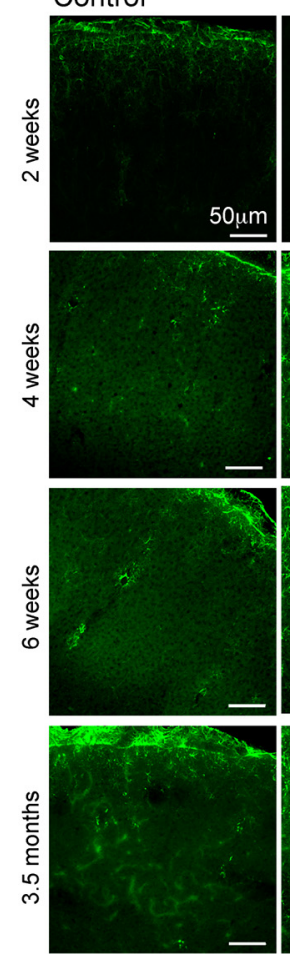

2 weeks

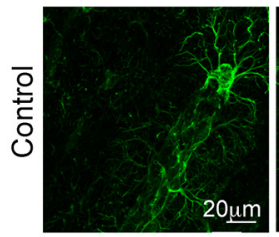

C

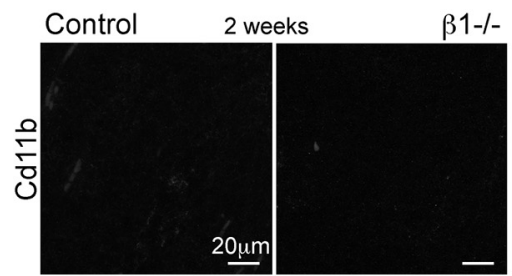

$\beta 1-/-$
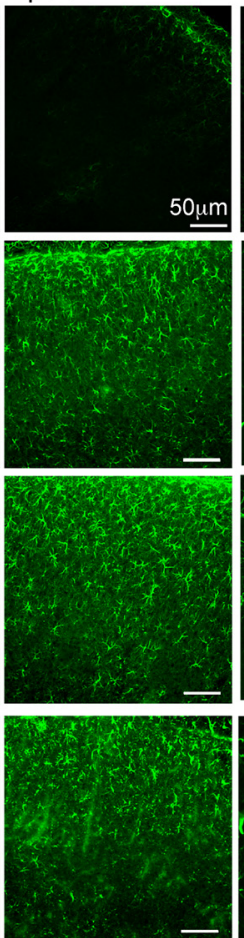

4 weeks
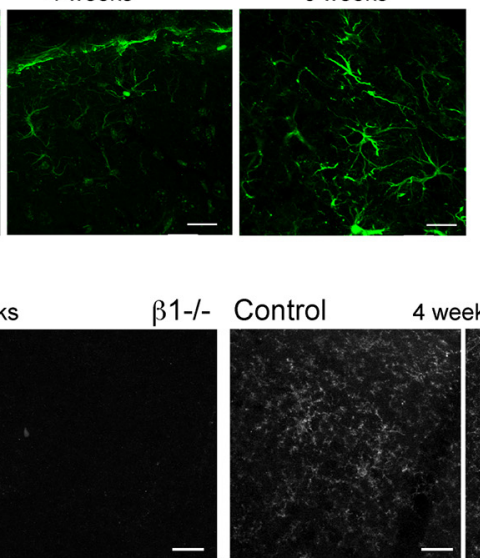
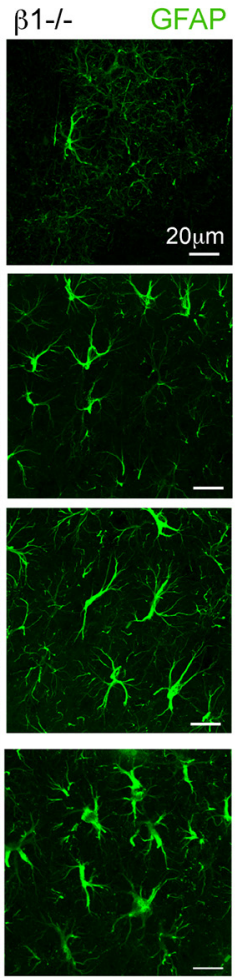

6 weeks

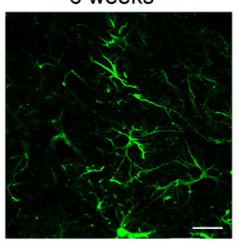

weeks

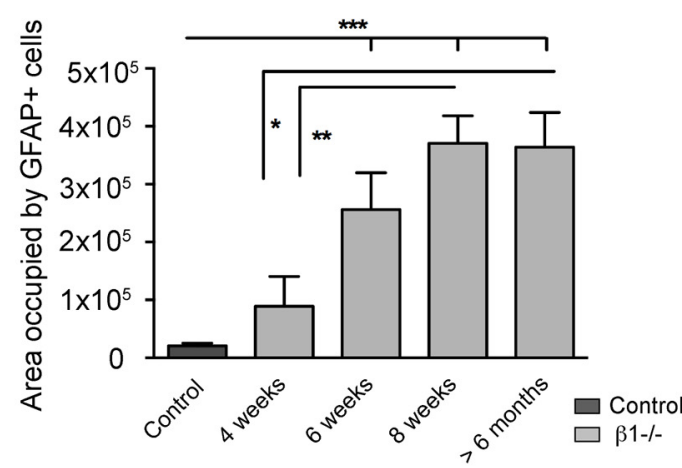

b

Control $\beta 1-/-\quad$ Control $\beta 1-/-\quad$ Control $\beta 1-/-$
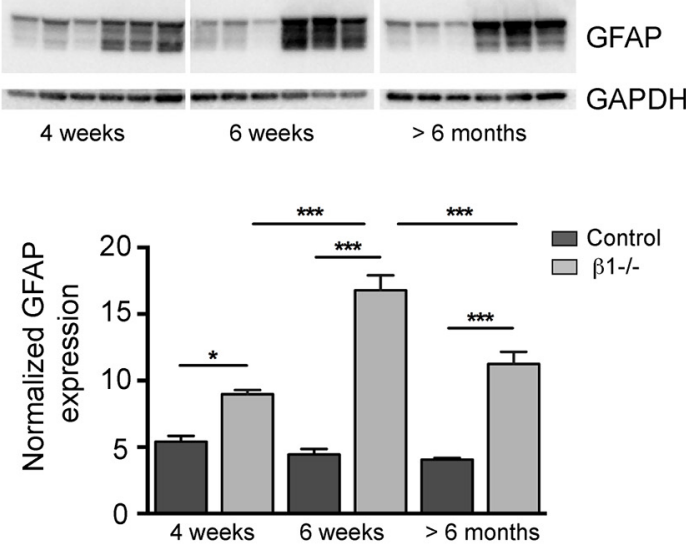

$\square$ Contro

$\square$ 阝1-/-

$\beta 1-/-$ Control 6 weeks
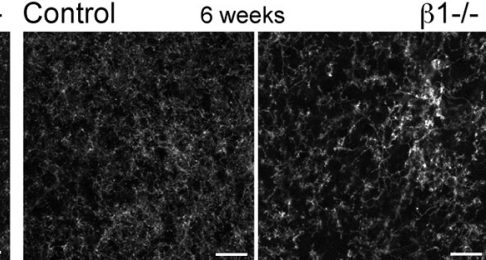

Figure 1. Mice with deletion of $\beta 1$-integrin $\left(\beta 1^{-/-}\right)$develop widespread reactive astrogliosis and mild secondary microgliosis. $\boldsymbol{a}$, Immunohistochemistry against the intermediate filament GFAP in the cortical gray matter of $\beta 1$-integrin-deficient and control mice at 2,4 , and 6 weeks and 3.5 months of age. GFAP levels are comparably low at 2 weeks of age, but progressively increase in $\beta 1^{-1-}$ mice of 4 and 6 weeks and 3.5 months of age. Cell bodies and main processes appear strongly hypertrophied in $\beta 1^{-1-}$ mice at 6 weeks of age and older (high magnification). In controls, GFAP-positive nonhypertrophied astrocytes can be found close to the meninges and surrounding large blood vessels (high magnification). Quantification of the area occupied by GFAP ${ }^{+}$cells revealed significant differences between control $(n=23)$ and $\beta 1^{-1-}$ mice older than 6 weeks ( 4 weeks of age, $n=3 ; 6$ weeks of age, $n=9 ; 8$ weeks of age, $n=10 ;>6$ months of age, $n=$ 6; one-way ANOVA followed by Tukey's multiple comparison test). $\boldsymbol{b}$, Western blot analysis and quantification of GFAP at 4 and 6 weeks and $>6$ months of age. $\boldsymbol{c}$, Immunohistochemistry against the microglial receptor $\mathrm{Cd} 11 \mathrm{~b}$ in $\beta 1^{-I-}$ and control mice at 2, 4, and 6 weeks of age. Staining intensity is increased in $\beta 1^{-1-}$ mice at 6 weeks of age indicating microglia activation. Error bars refer to SEM. Statistical significance with ${ }^{*} p<0.05,{ }^{* *} p<0.01$, and ${ }^{* * *} p<0.001$.

EEGs (22-258 h continuous recording) were recorded while simultaneously videotaping each animal (see Table 1 for a list of all $\beta 1^{-1-}$ animals and respective recording times).

We observed highly abnormal EEG activity in $\beta 1^{-/-}$mice compared with their control littermates (Fig. 2a). This activity consisted of tonic-clonic seizures accompanied by a clear convulsive phenotype (Fig. $2 b, d$ ) and frequent interictal spiking (Fig. $2 c, e)$. Tonic-clonic seizures were exhibited by $58 \%$ of $\beta 1^{-l-}$ animals (29/50 mice), while seizures were never observed in control littermates (0/48 mice). We recorded EEGs in four different age groups (4 and 5-6 weeks, 2-3 months, and older than 6 months), and found that the seizure incidence was highest in 5 - to 6-weeks-old animals (Fig. 2f). However, seizure frequency was not significantly different between age groups (ROUT outlier test, Kruskal-Wallis test, $p=0.297$, Dunn's multiple comparison test; Fig. $2 g$ ). Given that seizures occurred on average only once every $1-2 \mathrm{~d}$, it is possible that the recording periods were not always long enough to compute an accurate seizure frequency (Table 1). Thus, we might overestimate the number of animals without seizures.

In contrast, we observed age-dependent interictal spiking in almost all $\beta 1^{-/-}$mice, which increased dramatically in older 
Table 1. Time span of EEG recordings, seizure number, and seizure frequency are listed for EEG-recorded $\beta 1^{-/-}$mice

\begin{tabular}{|c|c|c|c|}
\hline Animal tag & Recorded time (h) & \# of seizures & Seizure frequency \\
\hline \multicolumn{4}{|c|}{4 weeks of age } \\
\hline 1689 & 53.58 & 0 & 0.000 \\
\hline 1696 & 53.58 & 0 & 0.000 \\
\hline 1698 & 22 & 0 & 0.000 \\
\hline 1700 & 53.58 & 1 & 0.019 \\
\hline 3125 & 163 & 0 & 0.000 \\
\hline No ET 1 & 163 & 0 & 0.000 \\
\hline No ET 2 & 163 & 2 & 0.012 \\
\hline 3165 & 257.93 & 24 & 0.093 \\
\hline 3166 & 257.93 & 11 & 0.043 \\
\hline \multicolumn{4}{|c|}{6 weeks of age } \\
\hline 714 & 65.78 & 7 & 0.106 \\
\hline 704 & 65.78 & 9 & 0.137 \\
\hline 705 & 65.78 & 7 & 0.106 \\
\hline 707 & 65.78 & 7 & 0.106 \\
\hline 1851 & 69.55 & 0 & 0.000 \\
\hline 1852 & 69.55 & 0 & 0.000 \\
\hline 1854 & 69.55 & 0 & 0.000 \\
\hline 1857 & 39.95 & 0 & 0.000 \\
\hline 1864 & 69.55 & 2 & 0.029 \\
\hline 2152 & 78 & 4 & 0.051 \\
\hline 2159 & 78 & 5 & 0.064 \\
\hline 2175 & 78 & 2 & 0.026 \\
\hline 2176 & 78 & 1 & 0.013 \\
\hline 2171 & 78 & 1 & 0.013 \\
\hline \multicolumn{4}{|c|}{ 2-3 months of age } \\
\hline 1614 & 52.2 & 13 & 0.249 \\
\hline 1615 & 52.2 & 5 & 0.096 \\
\hline 1623 & 52.2 & 0 & 0.000 \\
\hline 1630 & 52.2 & 0 & 0.000 \\
\hline 2230 & 67 & 2 & 0.030 \\
\hline 2208 & 67 & 0 & 0.000 \\
\hline 2210 & 67 & 0 & 0.000 \\
\hline 188 & 77.46 & 2 & 0.026 \\
\hline 201 & 88.36 & 2 & 0.023 \\
\hline 236 & 67.86 & 0 & 0.000 \\
\hline 239 & 69.6 & 0 & 0.000 \\
\hline 578 & 99.44 & 1 & 0.010 \\
\hline 579 & 99.44 & 1 & 0.010 \\
\hline 581 & 99.44 & 4 & 0.040 \\
\hline 582 & 99.44 & 3 & 0.030 \\
\hline \multicolumn{4}{|c|}{$>6$ months of age } \\
\hline 256 & 52 & 12 & 0.231 \\
\hline 265 & 52 & 0 & 0.000 \\
\hline 268 & 52 & 0 & 0.000 \\
\hline 818 & 69.5 & 5 & 0.072 \\
\hline 866 & 69.5 & 1 & 0.014 \\
\hline 909 & 69.5 & 0 & 0.000 \\
\hline 911 & 69.5 & 3 & 0.043 \\
\hline 917 & 69.5 & 0 & 0.000 \\
\hline 923 & 69.5 & 5 & 0.072 \\
\hline
\end{tabular}

EEGs were recorded from a corresponding number of control animals in each age group.

mice (ROUT outlier test, one-way ANOVA, $p \leq 0.0001$, Tukey's multiple comparison test; Fig. $2 h$ ). Only $14 \%$ of $\beta 1^{-/-}$mice showed none or little interictal spiking, whereas the remaining $86 \%$ have considerably higher values $(n=43)$ when compared with littermate controls $(n=20)$. Half of the $\beta 1^{-1-}$ mice $(3 / 6)$ with little or no interictal spiking were 4 weeks of age, the age group presenting with less severe astrogliosis. This suggests a high penetrance of the phenotype at least with regard to interictal spiking and GFAP expression (7\% of the mice analyzed by immunohistochemistry showed GFAP expression comparable to controls while all other animals had elevated GFAP levels in the cortical gray matter, $n=28$ ).

To assess a correlation between GFAP immunohistochemistry and seizure frequency, the Spearman correlation coefficient between these two variables was computed. The coefficient of $\rho=$ $0.37(p=0.006)$ indicates that GFAP levels and seizure frequency tend to increase together.

We were unable to conduct continuous EEG recordings on mice younger than 4 weeks since animals are housed separately after cranial electrode implantation, and therefore they had to be of weaning age for surgery. In addition, we waited $\sim 5 \mathrm{~d}$ after implantation before recording. We observed that $\beta 1^{-1-}$ mice often weakened and showed weight loss after several days of recording. These animals were removed from further recording.

It can be difficult to place EEG electrodes on the brain surface without them penetrating into the brain or injuring the meninges, which can cause astrocyte and microglia activation. In a subset of control and $\beta 1^{-/-}$animals, we found that implantation of the electrodes had caused tissue damage (Fig. 3). To assess how this acute injury affects seizures in control and $\beta 1^{-/-}$mice, we identified the group of animals that had incurred additional damage based on GFAP and Cd11b immunohistochemistry. We divided the animals into three groups: animals without damage, animals with mild damage, or animals with severe damage. In animals without tissue damage we did not observe microglia activation as assessed by Cd11b levels (Fig. $3 a$ ). Note that the microglia activation and the concomitant increase in Cd11b immunoreactivity caused by electrode damage by far exceeds the mild microglia activation that we normally observe in $\beta 1^{-1-}$ animals (Robel et al., 2009). This allowed us to identify electrodeinjured brain areas despite high GFAP levels in $\beta 1^{-/-}$mice (Fig. $3 b)$. In mice with mild injury electrodes had not penetrated the brain tissue but Cd11b (and GFAP in controls) was upregulated when compared with neighboring brain areas. In animals with severe damage, electrodes had penetrated the brain tissue.

We then compared seizure and interictal spiking frequencies between animals with and without additional acute tissue damage. We never observed seizures in control animals. More specifically, 10 control animals with acute damage (Fig. $3 c$, mild and severe) were recorded for a total of $769 \mathrm{~h}$ and six of these mice were recorded again 4-6 weeks later for a total of $331 \mathrm{~h}$. The lack of seizures in control mice suggests that inflammation induced by this acute and locally confined injury was not sufficient to trigger epileptogenesis at least during our observation period of up to 8 weeks after electrode implantation.

To ensure that the acute injury and chronic astrogliosis in $\beta 1^{-/-}$mice do not have a synergistic effect on seizure and spiking frequency, we compared $\beta 1^{-/-}$with and without electrode damage. There was no significant difference in interictal spiking or seizure frequencies between these groups (Fig. 3c).

These data show that chronic astrogliosis in $\beta 1^{-1-}$ mice is associated with abnormal EEG activity representative of interictal spiking and spontaneous seizures in a majority of mice while focal gliosis resulting from a localized acute injury does not cause epilepsy.

\section{Neuronal hyperexcitability characterizes $\beta 1^{-/-}$mice}

Epileptic seizures result from abnormal changes in neuronal excitability (Goldberg and Coulter, 2013). To examine whether this was the case in $\beta 1^{-/-}$animals, we performed whole-cell patchclamp recordings on layer II/III cortical pyramidal neurons in acute brain slices of mice $4-6$ and 6-8 weeks old. We found that 
a

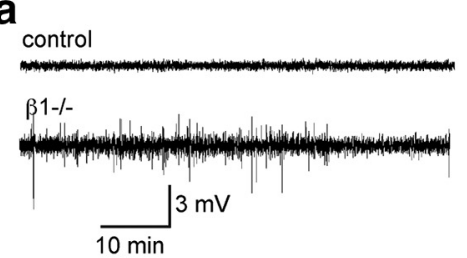

d

entering seizure

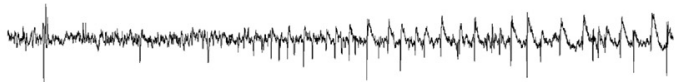

last part of seizure

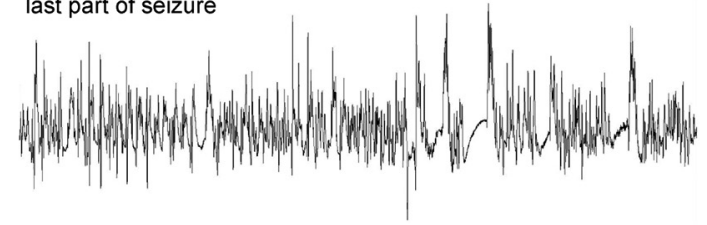

b

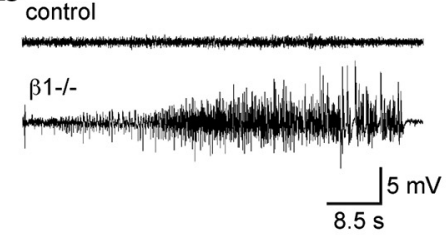

C

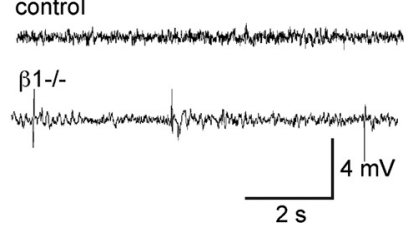

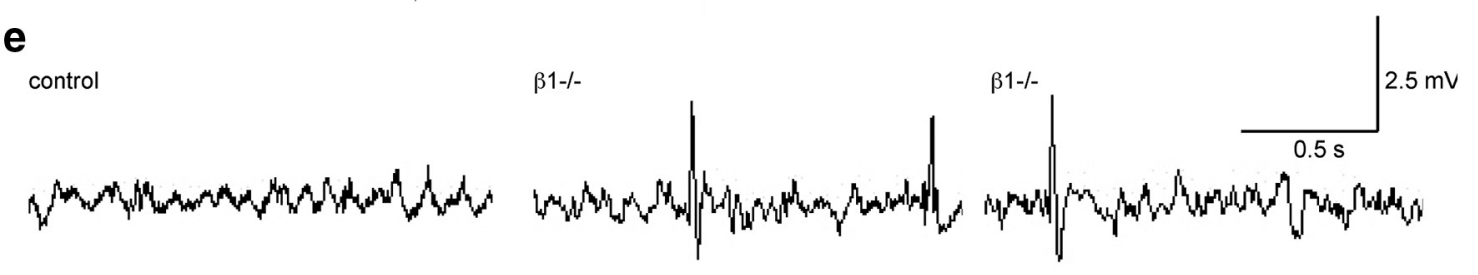

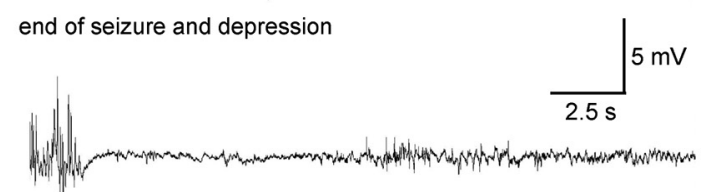

f

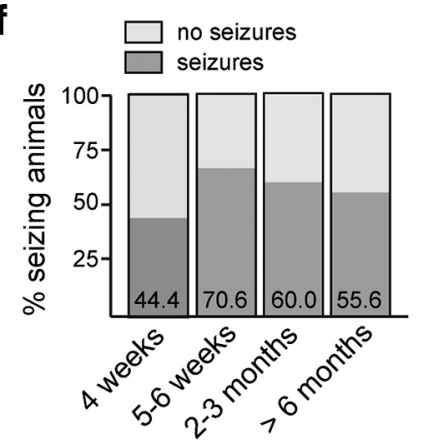

g

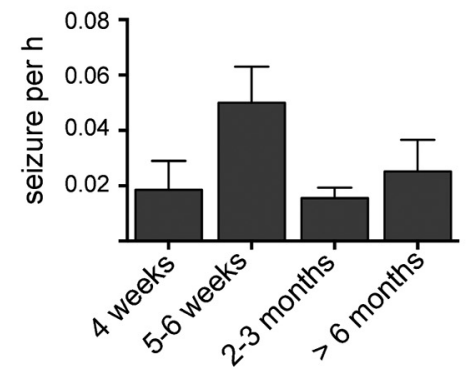

h

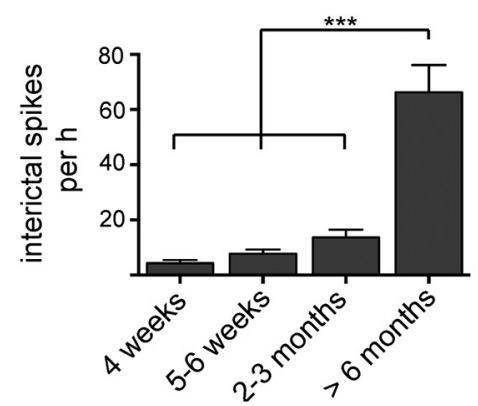

Figure 2. Mice with chronic astrogliosis develop spontaneous seizures and interictal spiking. $\boldsymbol{a}$, EEG recordings reveal abnormal EEG activity in $\beta 1^{-/-}$mice when compared with control mice. $\boldsymbol{b}$, Abnormal activity in $\beta 1^{-/-}$mice manifests in spontaneous tonic-clonic seizures or in interictal spiking (c). $\boldsymbol{d}$, High temporal resolution of the start of a seizure. At the end of the seizure, EEG signal depression is typically observed. $\boldsymbol{e}$, High temporal resolution of an interictal spike. $\boldsymbol{f}$, The percentage of seizing animals is lowest at 4 weeks of age and increases in older animals. $\boldsymbol{g}, \beta 1-1-$ mice experience an average of one to two seizures within $48 \mathrm{~h}$. Seizure frequency is not significantly different between age groups. $\boldsymbol{h}$, Interictal spiking occurs at a high frequency in all age groups and is significantly increased in $\beta 1^{-1-}$ mice older than 6 months. Error bars refer to SEM. Statistical significance with ${ }^{*} p<0.05,{ }^{* *} p<0.01$, and ${ }^{* * *} p<0.001$.

the neuronal RMP was significantly more depolarized in $\beta 1^{-1-}$ neurons $(4-6$ weeks: $\mathrm{RMP}=-63.28 \pm 1.77 \mathrm{mV}, n=$ 32; $6-8$ weeks: $\mathrm{RMP}=-68.87 \pm 1.38 \mathrm{mV}, n=30)$ than in controls (4-6 weeks: RMP $=-71.83 \pm 0.8 \mathrm{mV}, n=35$, two-tailed unpaired $t$ test, $p<0.0001 ; 6-8$ weeks: RMP $=$ $-73.03 \pm 0.77, n=32$, two-tailed unpaired $t$ test, $p=0.0002$; Fig. $4 a$ ), while the input resistances were higher in 4 - to 6 -week-old $\beta 1^{-1-}$ mice (control $R_{i}=102.6 \pm 8.28 \mathrm{M} \Omega$, $\beta 1^{-/-} R_{i}=137.9 .36 \mathrm{M} \Omega$, two-tailed Mann-Whitney test, $p=$ 0.0014 ; Fig. $4 b$ ) but comparable between both groups at $6-8$ weeks of age (control $R_{i}=78.38 \pm 7.97 \mathrm{M} \Omega, \beta 1^{-1-} R_{i}=$ $84.86 \pm 5.55 \mathrm{M} \Omega$, two-tailed Mann-Whitney test, $p=0.1016$; Fig. $4 b)$.

To examine whether $\beta 1^{-/-}$pyramidal neurons are hyperexcitable, we chose four different approaches. First, we determined the latency of the development of ictal (defined as events longer than $2 \mathrm{~s}$ ) and of interictal (defined as events with a duration between $500 \mathrm{~ms}$ and $2 \mathrm{~s}$ ) activity following removal of $\mathrm{Mg}^{2+}$ from the bath solution allowing for the removal of the $\mathrm{Mg}^{2+}$ block from the NMDA receptor as previously described (Buckingham et al., 2011). In control mice, latency to the first interictal event was $23.69 \pm 3.25 \mathrm{~min}$ at $4-6$ weeks $(n=12)$ and $15.49 \pm 2.29 \min (n=14)$ at $6-8$ weeks of age (Fig. $4 c-e$ ). The onset of ictal discharges was $58.24 \pm 8.69 \mathrm{~min}$ $(n=9)$ and $37.93 \pm 2.53 \mathrm{~min}(n=9)$ at $6-8$ weeks of age (Fig. $4 c-e)$. Some neurons did not respond with ictal discharges within the recording period of 60-90 min. Nonresponsive neurons were excluded from the analysis since we could not determine the onset time. There were more nonresponding neurons in control brain slices compared with slices obtained from $\beta 1^{-1-}$ mice, suggesting that the mean value for ictal onset in control animals is likely underestimated. Pyramidal neurons in $\beta 1^{-/-}$brain slices showed a significantly shorter latency to onset of interictal (4-6 weeks: $12.04 \pm 2.82 \mathrm{~min}$, 
$n=12$, two-tailed unpaired MannWhitney test, $p=0.0015 ; 6-8$ weeks: $8.64 \pm 0.91 \mathrm{~min}, n=10$, two-tailed unpaired $t$ test, $p=0.0243)$ and ictal $(4-6$ weeks: $21.43 \pm 4.94 \mathrm{~min}, n=10$, twotailed unpaired Mann-Whitney test, $p=0.0095 ; 6-8$ weeks: $15.27 \pm 1.78$ $\min , n=10$, two-tailed unpaired $t$ test, $p \leq 0.0001)$ activity in both age groups (Fig. $4 c-e$ ).

Similarly, we determined the latency of the development of ictal and of interictal activity following application of bicuculline, which is a $\mathrm{GABA}_{\mathrm{A}}$ receptor antagonist facilitating excitatory synchronization (Gutnick et al., 1982). Whereas the onset of interictal events was unchanged between controls and $\beta 1^{-/-}$at $4-6$ weeks of age (Fig. 4f, control; $8.33 \pm 1.54 \mathrm{~min}$, $n=10 ; \beta 1^{-1-} ; 6.1 \pm 0.59 \mathrm{~min}, n=14$, two-tailed unpaired Mann-Whitney test, $p=0.54$ ), the onset of ictal events was significantly faster in $\beta 1^{-/-}$pyramidal cells (control: $17.21 \pm 3.25 \mathrm{~min}, n=8$; $\beta 1^{-1-}: 10.27 \pm 1.58 \mathrm{~min}, n=15$, twotailed unpaired $t$ test, $p=0.041$ ).

Moreover, we quantified the number of action potentials fired in response to current injections. We found that this number was significantly greater in $\beta 1^{-/-}$pyramidal cells than in control neurons in response to 180, 200, 220, and 240 pA current injection (Fig. $4 g, h$ ), indicating a lowered excitability threshold in $\beta 1^{-1-}$ neurons of both age groups.

Last, we recorded input/output curves in control and $\beta 1^{-/-}$cortical slices. A stimulus electrode was used to deliver incrementally increasing stimuli to deep cortical layer IV, and postsynaptic currents were recorded in the superficial cortical layers (II/III). Input/output curves were constructed of the response area and amplitude as a function of stimulus intensity (Fig. 4i). Recordings from $\beta 1^{-/-}$ pyramidal cells were significantly larger than controls. Increasing stimulation resulted in greater excitatory response areas in $\beta 1^{-1-}$ slices compared with controls (Fig. $4 i$; two-way ANOVA followed by Sidak's multiple comparison test, $n=5$ for each genotype).

Fast synaptic excitation relevant to epilepsy is largely mediated by AMPA receptors, and AMPA receptor antagonists can reduce epileptiform activity in animal models and human epilepsy (Rogawski, 2013). To address whether AMPA receptor expression was changed in $\beta 1^{-1-}$ mice, we performed a Western blot analysis for the GluR2/3 subunit. At 4 and 6 weeks of age, protein levels were not significantly changed between control and $\beta 1^{-/-}$mice. In older animals, Glu2/3 levels were slightly reduced

b

C
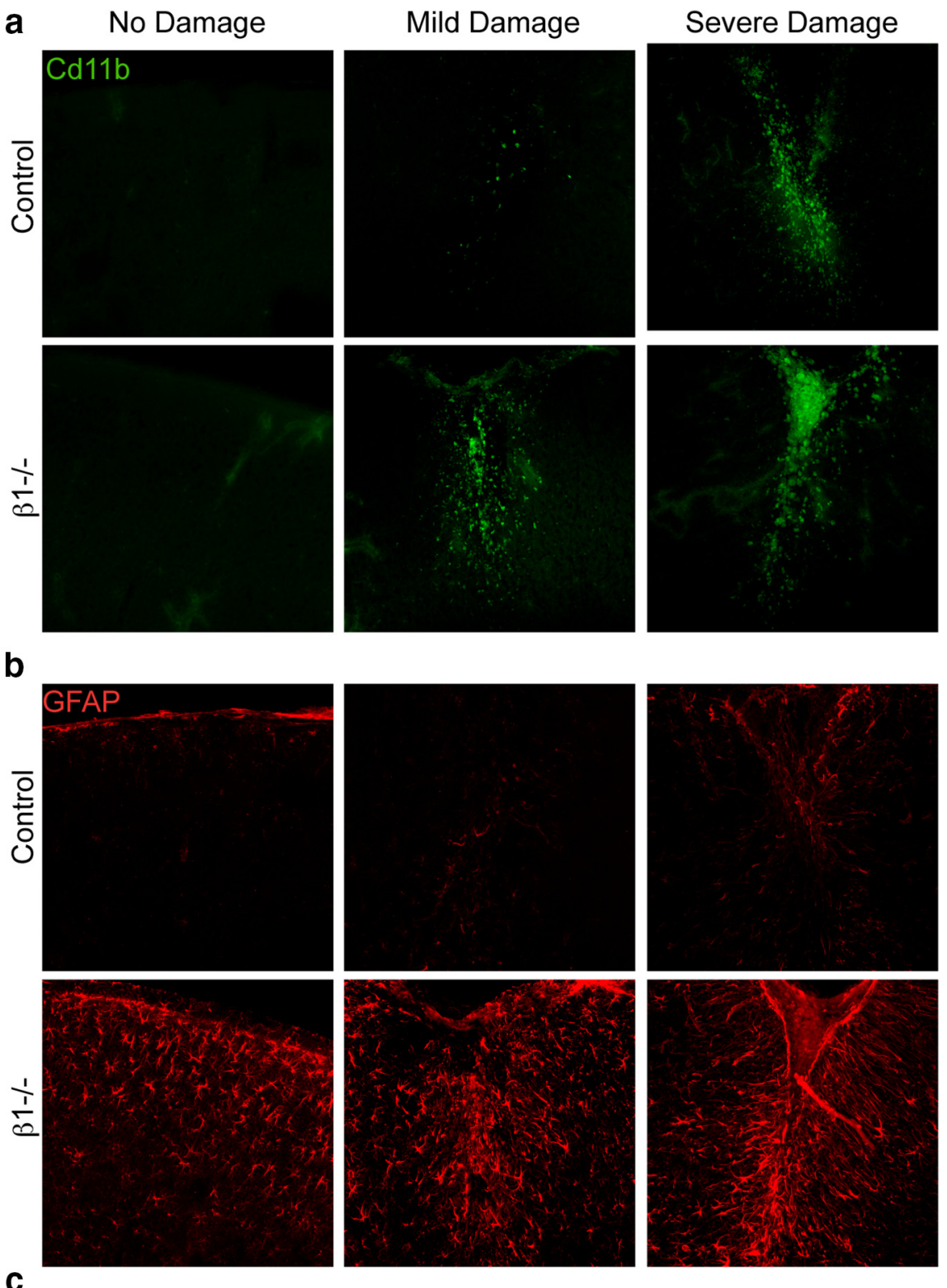

\begin{tabular}{|c|c|c|c|}
\hline & No Damage & Mild Damage & Severe Damage \\
\hline Control $(n=23)$ & $61 \%$ & $13 \%$ & $26 \%$ \\
\hline$\beta 1--(n=28)$ & $71 \%$ & $14.5 \%$ & $14.5 \%$ \\
\hline
\end{tabular}
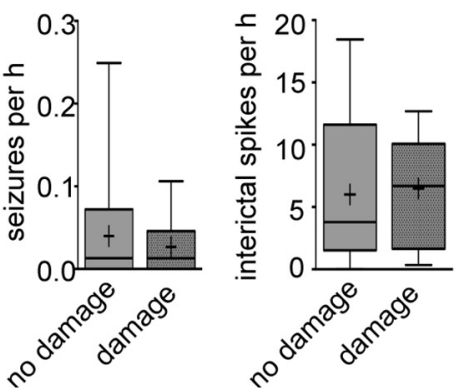

Figure 3. Tissue damage caused by electrode implantation does not affect the seizure phenotype. Immunohistochemistry for $\mathrm{Cd} 11 \mathrm{~b}$ as a marker of reactive microglia $(\boldsymbol{a})$ and GFAP in $\beta 1^{-/-}$and control mice that had undergone electrode implantation and EEG recordings $(\boldsymbol{b})$. $\boldsymbol{c}$, Quantification of animals without tissue damage or mild and severe tissue damage. $\beta 1^{-l-}$ mice were divided in two groups based on whether or not tissue damage was detected. Seizure and interictal spiking frequencies were computed and did not differ significantly (seizures: with damage, $n=8$; without damage, $n=$ 22; Mann-Whitney, $p=0.86$; interictal spikes: with damage, $n=5$; without damage, $n=11$; Mann-Whitney, $p=0.48$; animals $>6$ months were excluded from the analysis since the frequency of interictal spikes is significantly higher at this age). Box-and-whisker plots display minimum to maximum values, and mean is shown as + . 

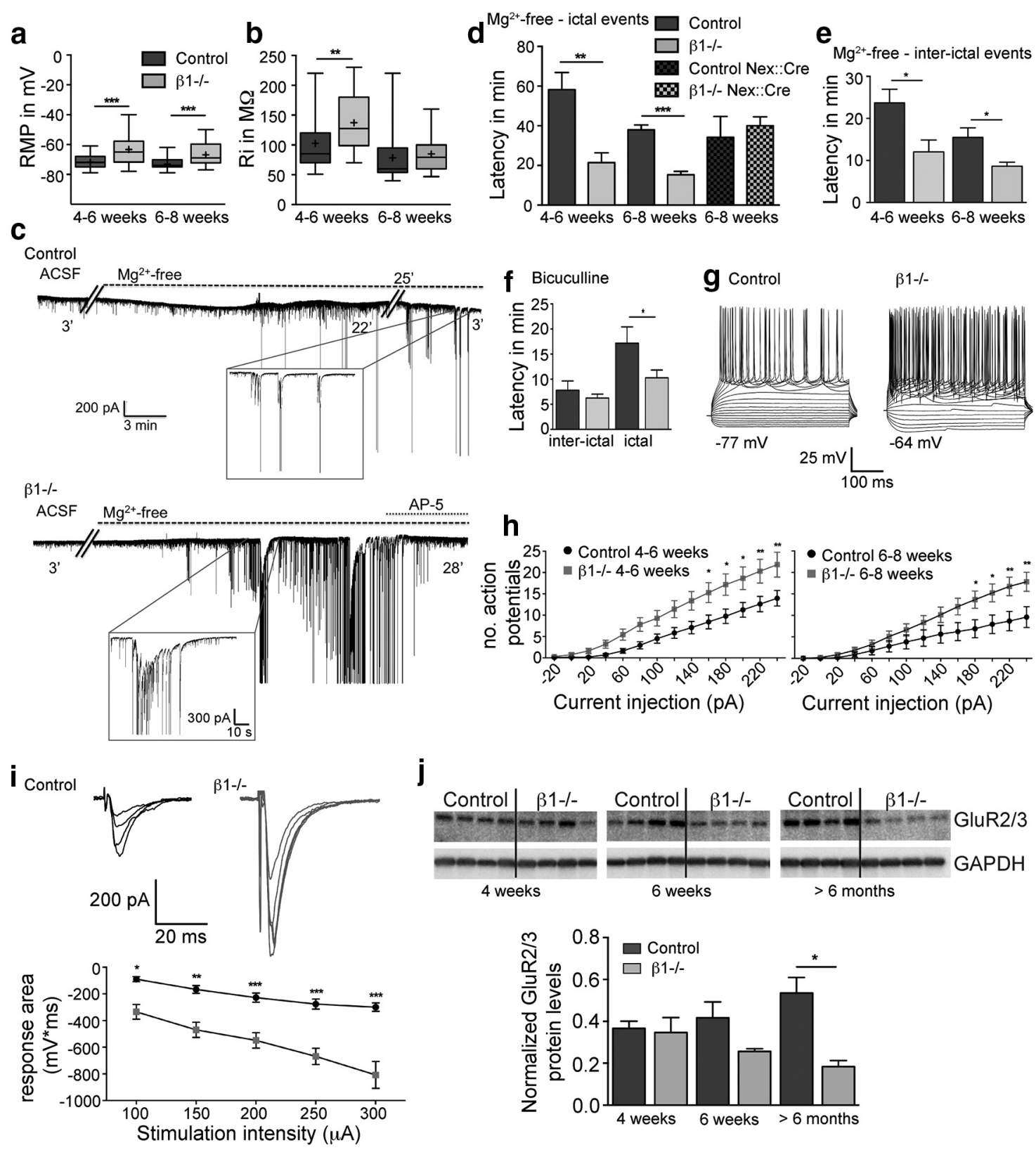

Figure 4. Layer II/III pyramidal neurons are hyperexcitable in mice with chronic astrogliosis. $\boldsymbol{a}$, The RMP of Layer II/III pyramidal neurons is significantly depolarized in acute slices of $\beta 1^{-1-}$ mice compared with controls. $\boldsymbol{b}$, The input resistance differs at 4 weeks of age but is unchanged in $\beta 1^{-/-}$neurons compared with controls. Whiskers in box-and-whisker plots show minimum to maximum values. The middle line is plotted at the median. c, Whole-cell patch-clamp recordings from pyramidal neurons before (ACSF) and after removal of $\mathrm{Mg}^{2+}\left(\mathrm{Mg}^{2+}\right.$-free) followed by AP-5 shows a faster onset and longer duration of ictal ( $>2$ s in duration) events in acute slices of $\beta 1^{-1-}$ mice compared with controls at $6-8$ weeks of age. $d$, Quantification of the latency to onset of ictal events (defined as events of $>2$ s in length) after removal of $\mathrm{Mg}^{2+}$ in $\beta 1^{-1-}$ mice and littermate controls, as well as in $\beta 1^{-1-}$ Nex::Cre mice and their littermate controls. $\boldsymbol{e}$, Quantification of the latency to onset of interictal (defined as events of $500 \mathrm{~ms}$ to 2 s length) after removal of $\mathrm{Mg}^{2+} . \boldsymbol{f}$, Quantification of the latency to onset of interictal and ictal events after bicuculline application. $\boldsymbol{g}$, Examples of voltage responses to increasing amplitude current injections, from -100 to $+240 \mathrm{pA}$ (in $20 \mathrm{pA} \mathrm{steps)} \mathrm{in} \mathrm{whole-cell,} \mathrm{current-clamped} \mathrm{pyramidal} \mathrm{peritumoral} \mathrm{neurons} \mathrm{in} \beta 1^{-/-}$and controls. $\boldsymbol{h}$, The average action potential number obtained in response to -20 to $240 \mathrm{pA}$ current pulses was plotted as a function of applied current yielding the input- output curves shown. $\boldsymbol{i}$, Graphical display of input/output curves of postsynaptic potentials recorded by whole-cell patch-clamp recording from pyramidal cells in superficial cortical layer II/III and the response area as a function of stimulation intensity in $\mathrm{b} 1^{-1-}$ and control cortical slices. $\boldsymbol{j}$, Western blot of the GluR2/3 subunit of the AMPA receptor. Error bars refer to SEM. Box-and-whisker plots display minimum to maximum values, and mean is shown as + . Statistical significance with ${ }^{*} p<0.05,{ }^{* *} p<0.01$, and ${ }^{* * *} p<0.001$.

(Fig. 4j). This excludes an increase in GluR2/3 protein expression levels as a contributor for seizure generation in $\beta 1^{-1-}$ mice.

\section{Neuronal deletion of $\boldsymbol{\beta} 1$-integrins does not induce} neuronal hyperexcitability

To exclude the possibility that neurons rather than astrocytes were selectively affected by the $\beta 1$-integrin deletion, we performed the same experiments in mice where $\beta 1$-integrin deletion was neuron specific. To mediate recombination of the floxed $\beta 1$-integrin gene, $\beta 1^{\mathrm{f} / \mathrm{fl}}$ mice were bred to Nex::Cre ${ }^{+/-}$mice, which express Cre under the control of regulatory sequences of the transcription factor Nex (Goebbels et al., 2006). This leads to genetic deletion in intermediate progenitors and neurons of the dorsal telencephalon at $\sim$ E11.5 (Goebbels et al., 2006). We previously reported that astrogliosis was absent in these mice, despite the early downregulation of $\beta 1$-integrin proteins (Robel et al., 
2009). However, layer II/III pyramidal neuron whole-cell patchclamp recordings conducted in acute brain slices from $\beta 1$ integrin $^{\mathrm{fl} / \mathrm{fl}}$, Nex::Cre ${ }^{+/-}$mice and their control littermates $\left(\beta 1\right.$-integrin $^{\mathrm{fl} / \mathrm{wt}}, \mathrm{Nex}::_{\text {Cre }^{+/-}} ; \beta 1$-integrin ${ }^{\mathrm{fl} / \mathrm{fl}}$, Nex::Cre ${ }^{-/-} ; \beta 1$-integrin $^{\mathrm{fl} / \mathrm{wt}}$, Nex::Cre ${ }^{-1-}$ ) showed that there is a similar latency to epileptiform event onset (longer than $2 \mathrm{~s}$ ) in all genotypes following the removal of $\mathrm{Mg}^{2+}$ (Fig. $4 d$; control, $34.21 \pm 10.51 \mathrm{~min}, n=6$; $\beta 1$-integrin ${ }^{\mathrm{fl} / \mathrm{fl}}$, Nex::Cre ${ }^{+/-} 40.0 \pm 4.52 \mathrm{~min}, n=7$, two-tailed unpaired $t$ test, $p=0.6035$ ).

Since neuron-specific $\beta 1$-integrin deletion did not induce hyperexcitability, we conclude that astrogliosis causes $\beta 1^{-1-}$ pyramidal cells to become depolarized and hyperexcitable.

\section{Do reactive astrocytes in $\beta 1^{-/-}$mice have impaired $\mathrm{K}^{+}$homeostasis?}

To elucidate possible mechanisms underlying neuronal hyperexcitability and seizures in $\beta 1^{-1-}$ mice, we first focused on the well established, astrocytic homeostatic functions. It has been suggested that impairments in astrocytic potassium and glutamate homeostasis can contribute to neuronal hyperexcitability and seizure generation (Seifert et al., 2010). Thus, we used a combination of Western blot, immunohistochemistry, and electrophysiological recordings to assess whether potassium and glutamate uptake is intact in $\beta 1^{-1-}$ astrocytes.

Whole-cell astrocyte patch-clamp recordings were performed on acute brain slices obtained from $\beta 1^{-1-}$ or control mice at $6-8$ weeks of age. To identify astrocytes, these animals expressed eGFP under the control of the astrocyte-specific Aldh1l1 promoter (Cahoy et al., 2008; Fig. 5a). The mean input resistance (control $R_{i}=18.45 \pm 1.44 \mathrm{M} \Omega, n=57 ; \beta 1^{-/-} R_{i}=22.01 \pm 2.84$ $\mathrm{M} \Omega, n=39$; two-tailed Mann-Whitney test, $p=0.9985$; Fig. $5 b$ ) and the mean RMP (control RMP $=-78.08 \pm 0.47 \mathrm{mV}, n=32$; $\beta 1^{-/-} \mathrm{RMP}=-78.19 \pm 0.50 \mathrm{mV}, n=30$; two-tailed $t$ test, $p=$ 0.8713; Fig. $5 c$ ), were comparable between $\beta 1^{-/-}$and control astrocytes. However, cell capacitance, which correlates with cell size, was significantly increased in $\beta 1^{-/-}$astrocytes (control $\mathrm{C}=$ $10.54 \pm 0.91 \mathrm{pF}, n=45 ; \beta 1^{-1-} \mathrm{C}=12.98 \pm 0.87 \mathrm{pF}, n=42$; two-tailed Mann-Whitney test, $p=0.0158$; Fig. $5 d$ ), consistent with their hypertrophied phenotype.

Astrocytic potassium $\left(\mathrm{K}^{+}\right)$conductance and uptake is thought to be mediated by the barium-sensitive potassium channel Kir4.1 (Olsen and Sontheimer, 2008). To activate Kir4.1mediated currents in these cells, we used a specific voltage-step protocol as previously described (Olsen et al., 2007), and isolated these currents using $100 \mu \mathrm{M} \mathrm{Ba}^{2+}$, which specifically inhibits Kir channels at this concentration (Ransom and Sontheimer, 1995). A point-by-point subtraction of the corresponding whole-cell current was done to isolate the $\mathrm{Ba}^{2+}$-sensitive component (Kir current; Fig. 5e). We quantified the Kir current, $I_{\text {Kir }}$ (expressed in $\mathrm{pA} /$ $\mathrm{pF}$ ), as the $\mathrm{Ba}^{2+}$-sensitive conductance at $-140 \mathrm{mV}$, normalized to the whole-cell capacitance from these recordings (Fig. 5e). $I_{\text {Kir }}$ was significantly reduced in $\beta 1^{-/-}$astrocytes $\left(I_{\mathrm{Kir}}=-195.4 \pm 26.09\right.$ $\mathrm{pA} / \mathrm{pF}, n=26$ ) compared with controls (control $I_{\text {Kir }}=-257.4 \pm$ 20.7 pA/pF, $n=31$; two-tailed Mann-Whitney test, $p=0.0019$; Fig. $5 e$ ).

To assess whether this reduction in Kir currents impairs $\mathrm{K}^{+}$ uptake, we challenged astrocytes in $\beta 1^{-1-}$ and control acute brain slices with pressure-applied $\mathrm{K}^{+}(125 \mathrm{~mm} \mathrm{KCl})$, which induces an inward current under voltage-clamp conditions. The number of ions that moved across the membrane can be determined from the charge transfer, i.e., the area of the $\mathrm{Ba}^{2+}$-sensitive current induced by the puff. Surprisingly, there was no difference between $\beta 1^{-/-}$and control astrocytes in the number of $\mathrm{K}^{+}$ions moving across the membrane (control: $1.08 \pm 0.24 \mathrm{fmol} \mathrm{K}^{+}, n=13 ; \beta 1^{-/-}: 1.29 \pm$ 0.23, $n=11$, two-tailed unpaired $t$ test, $p=0.5438$; Fig. $5 f$ ).

We complemented these studies with immunohistochemical and Western blot analyses to address whether reduced Kir currents were a result of reduced levels of Kir4.1 protein. However, there were no significant differences in Kir4.1 protein expression (relative expression levels normalized to GAPDH) or distribution between $\beta 1^{-1-}$ and control animals at 4 and 6 weeks (Fig. $5 g, h)$. There were, however, differences in levels of Kir4.1 expression in control mouse parenchymal gray matter astrocytes. Most astrocytes showed low Kir4.1 levels within the fine processes; however, some astrocytes expressed higher Kir4.1 levels in cell bodies and processes. A similar pattern could be seen in brain slices from $\beta 1^{-/-}$mice (Fig. $5 g$ ). Kir current reduction seems to occur at a functional level and was not associated with reduced levels of Kir4.1 protein. Interestingly, Kir4.1 protein levels were increased in $\beta 1^{-/-}$animals $>6$ months old (Fig. $5 h$ ) possibly reflecting compensatory changes in $\beta 1^{-/-}$astrocytes at later stages.

In summary, reactive astrocytes in $\beta 1^{-/-}$mice show reduced Kir currents despite normal Kir4.1 protein levels. However, this did not significantly alter the resting membrane potential or $\mathrm{K}^{+}$ uptake. The latter may be due to the large, poorly localized $\mathrm{K}^{+}$ challenge. A reduced density of Kir channels on fine processes may, nevertheless, show impaired local $\mathrm{K}^{+}$homeostasis.

\section{Do reactive astrocytes in $\beta 1^{-/-}$mice show impaired glutamate homeostasis?}

To examine the possibility that glutamate uptake may be impaired in $\beta 1^{-1-}$ mice, we first analyzed expression of the two astrocytic glutamate transporters, Glt-1 (slcla2) and GLAST (slcla3), by immunohistochemistry and Western blot. Levels of both proteins were similar at 4 and 6 weeks of age (Fig. $6 a-c$ ). In $\beta 1^{-/-}$animals older than 6 months, Glt-1 levels were slightly reduced (Fig. $6 b$ ), whereas GLAST protein levels remained comparable between controls and $\beta 1^{-l-}$ mice at this age (Fig. 6b). There was no apparent difference in Glt-1 distribution between the 6-week-old control and $\beta 1^{-1-}$ mice (Fig. $6 a$; Lehre et al., 1995) on the differential expression of Glt-1 and GLAST).

To assess if glutamate transport is changed, whole-cell patchclamp recordings from $\mathrm{eGFP}^{+}$astrocytes were performed in acute brain slices from $\beta 1^{-/-}$or control mice. High glutamate concentrations $(200 \mu \mathrm{M})$ were applied using a puff pipette, and uptake currents were recorded in $\beta 1^{-/-}$astrocytes and controls while blocking $\mathrm{K}^{+}$uptake with $\mathrm{BaCl}_{2}$, and neuronal activity with TTX, D- AP5, bicuculline, and $\mathrm{CdCl}_{2}$. Recordings were repeated after blocking glutamate transporters with the inhibitors TBOA and DHK (Fig. $6 d$, traces). The amount of glutamate taken up computed as the TBOA/DHK-sensitive charge transfer (area under the curve) and was significantly reduced in $\beta 1^{-1-}$ astrocytes (Fig. $6 d$; control $0.0857 \pm 0.0123$ fmol glutamate, $n=6 ; \beta 1^{-/-}$ $0.0204 \pm 0.0120, n=5$, two-tailed unpaired $t$ test, $p=0.0045$ ).

Despite previous reports of a downregulation of the astrocytic enzyme glutamine synthetase in reactive astrocytes (Ortinski et al., 2010), we found comparable levels of this protein in the cortical gray matter of $\beta 1^{-l-}$ and control brains. We found glutamine synthetase (GS) protein levels to be significantly reduced in older mice of both genotypes (Fig. 6e).

These data suggest that impaired astrocytic uptake of glutamate may cause increased extracellular glutamate concentrations that could contribute to enhanced neuronal excitability. 
a

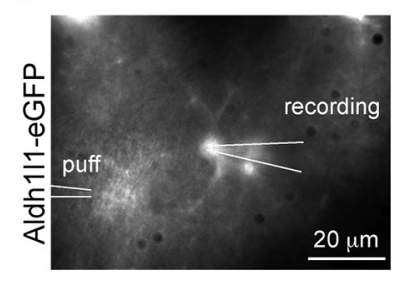

e

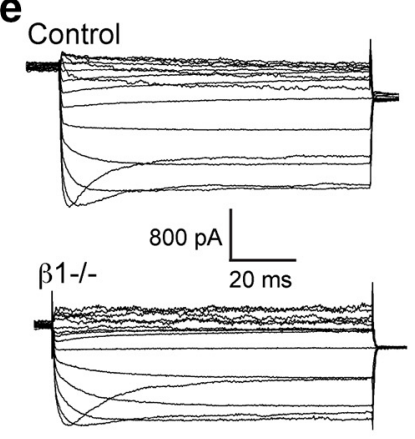

f

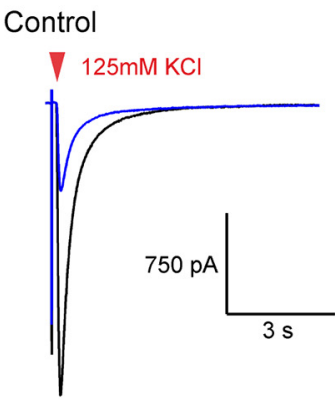

b

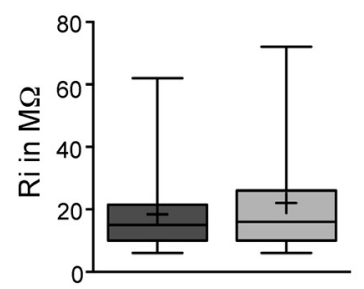

Control $\beta 1-/-$
C

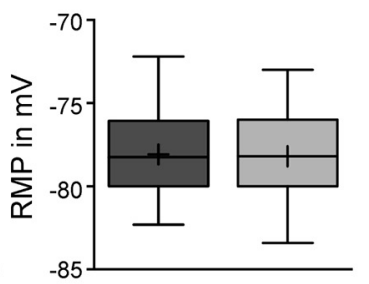

g

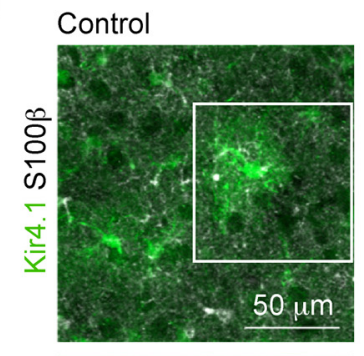

d

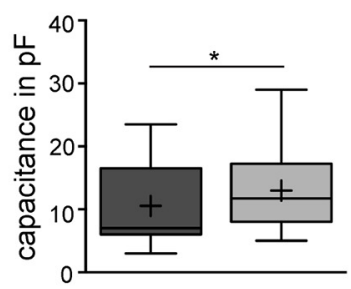

$\beta 1-/-$
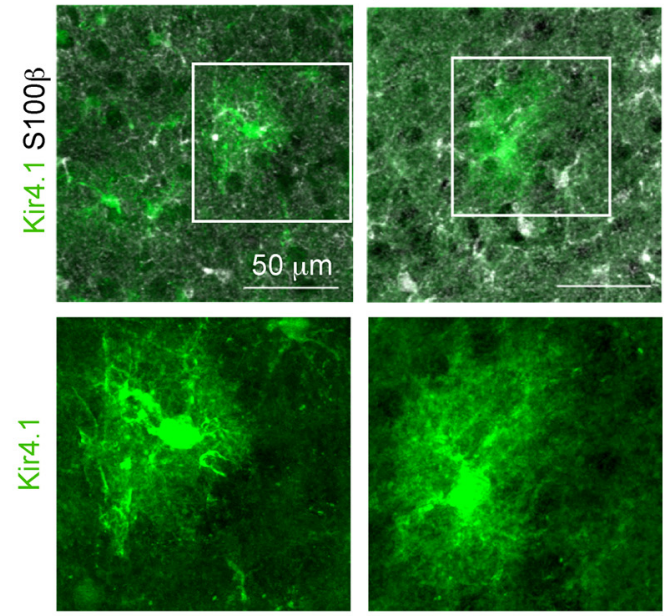

h

ACSF
$100 \mu \mathrm{M} \mathrm{BaCl} 2$
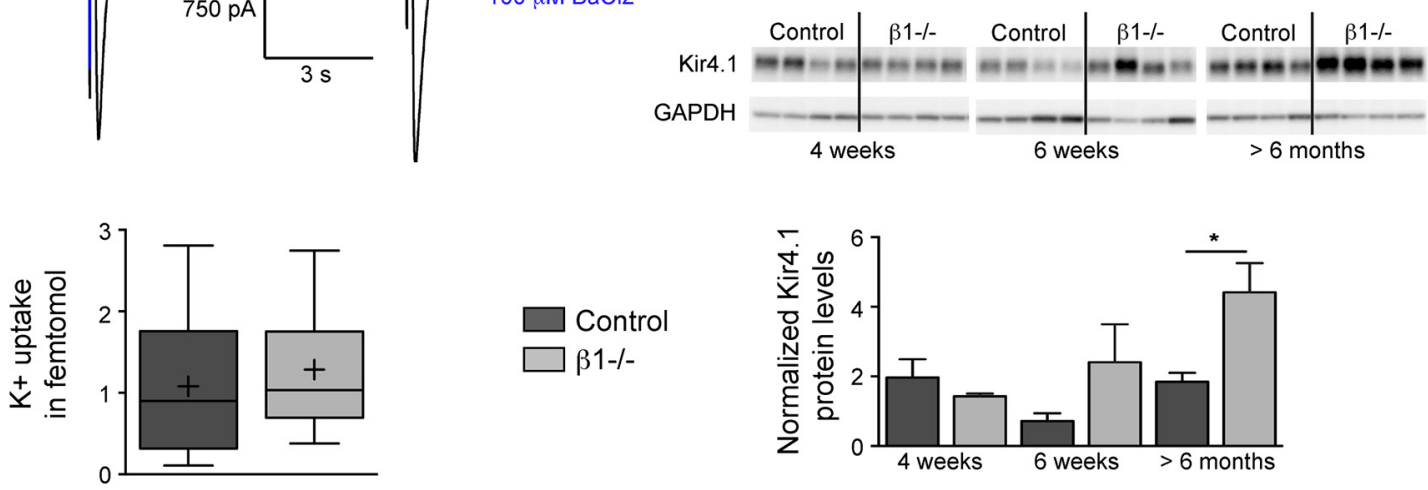

Control

$\beta 1-/-$

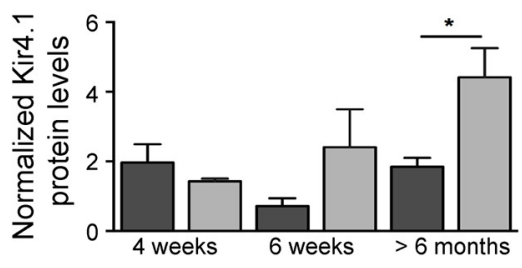

Figure 5. Potassium homeostasis is moderately impaired in mice with chronic astrogliosis. $\boldsymbol{a}$, For whole-cell patch-clamp recordings, astrocytes were identified by their eGFP in acute slices of $\beta 1^{-I-}$ and control mice ( $6-8$ weeks of age) carrying an allele expressing eGFP under the astrocyte-specific Aldh111 promoter. Placement of the recording pipette and puff pipette is indicated. $\boldsymbol{b}$, The input resistance $\left(R_{i}\right)$ and resting RMP (c) of parenchymal astrocytes in the cortical gray matter is unchanged between $\beta 1^{-/-}$and control mice. $\boldsymbol{d}$, The cell capacitance is increased in $\beta 1^{-/-}$ astrocytes. $\boldsymbol{e}$, To activate Kir4.1-mediated potassium currents in astrocytes a voltage-step protocol was used in ACSF and after bath application of the Kir4.1 inhibitor BaCl${ }_{2}$. Traces represent a point-by-point subtraction of the corresponding current traces isolating the $\mathrm{Ba}^{2+}$-sensitive component of the whole-cell current. Quantification of Kir currents $\left(I_{\text {Kir }}\right.$ in pA/pF) as the Ba ${ }^{2+}$-sensitive conductance at $-140 \mathrm{mV}$ normalized to the whole-cell capacitance revealed significantly reduced Kir4.1 currents in $\beta 1^{-/-}$astrocytes. $\boldsymbol{f}$, Potassium uptake was similar in $\beta 1^{-/-}$and control astrocytes after pressure application of $125 \mathrm{~mm} \mathrm{KCl}$ for $50 \mathrm{~ms}$. Whiskers in box-and-whisker plots show minimum to maximum values. The line in the middle of the box is plotted at the median, + indicates the mean. $\boldsymbol{g}$, The majority of astrocytes expresses Kir4.1 at lower levels in fine processes only. Few astrocytes express higher Kir4.1 levels in cell bodies and processes. $\boldsymbol{h}$, Western blot analysis probing for Kir4.1 protein showed similar levels of protein expression and distribution in the cortical gray matter of $\beta 1^{-/-}$and control mice at 6 weeks of age, but increased levels in older mice. Error bars in bar graphs refer to SEM. Statistical significance with ${ }^{*} p<0.05,{ }^{* *} p<0.01$, and ${ }^{* * *} p<0.001$.

\section{Chronic gliosis is associated with an immature expression profile of neuronal chloride transporters}

Recent studies have suggested that decreased inhibition, either from reduced GABA synthesis (Ortinski et al., 2010) or GABA acting as an excitatory instead of an inhibitory neurotransmitter, can contribute to neuronal hyperexcitability (Lee et al., 2011; Ben-Ari et al., 2012; Rangroo Thrane et al., 2013). The action of GABA on neurons depends on neuronal intracellular chloride concentrations. Mature neurons normally have a low intracellular chloride $\left[\mathrm{Cl}^{-}\right]_{\mathrm{i}}$ concentration resulting in hyperpolarizing GABA responses (Kahle et al., 2008). Neuronal $\left[\mathrm{Cl}^{-}\right]_{i}$ concentra- tions are maintained by the balanced expression of the cationchloride cotransporters (CCC) NKCC1 and KCC2. Immature neurons show high expression of NKCC1 relative to low KCC2 expression, which maintains a high $\left[\mathrm{Cl}^{-}\right]_{\mathrm{i}}$. A developmental expression level switch occurs during the second postnatal week in rodents. KCC2 levels increase and NKCC1 levels decrease, resulting in low $\left[\mathrm{Cl}^{-}\right]_{\mathrm{i}}$, and hyperpolarized responses after GABA binds to GABAA receptors (Kahle et al., 2008).

To determine whether CCC expression is changed in mice with chronic astrogliosis, we performed Western blots to detect KCC2 and NKCC1 (Fig. $7 a$ ) in $\beta 1^{-1-}$ and control cortical gray 

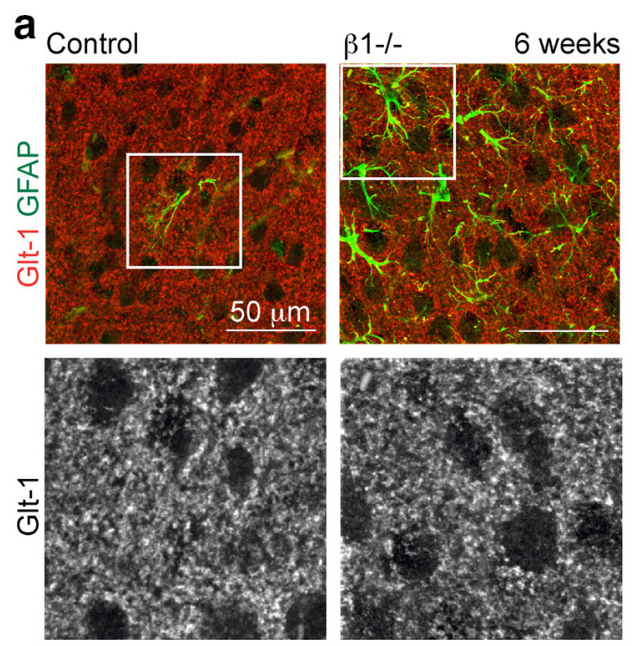

b
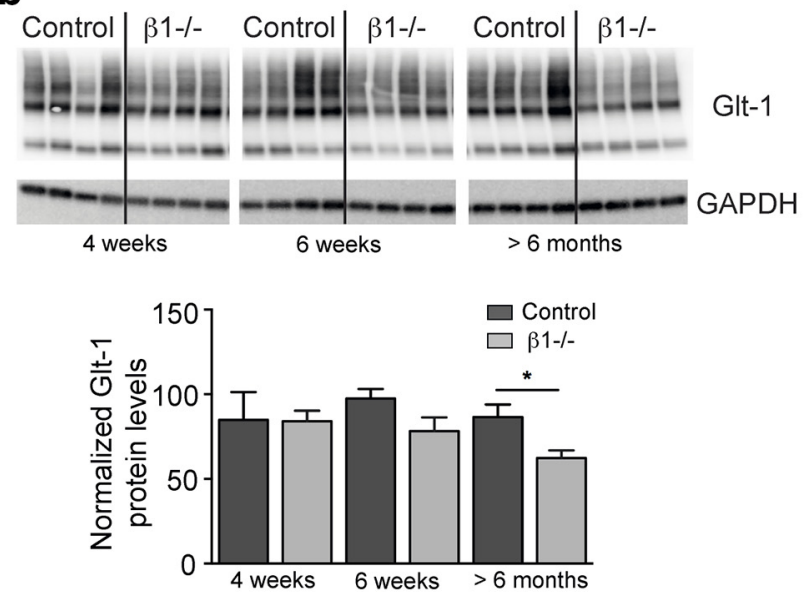

C
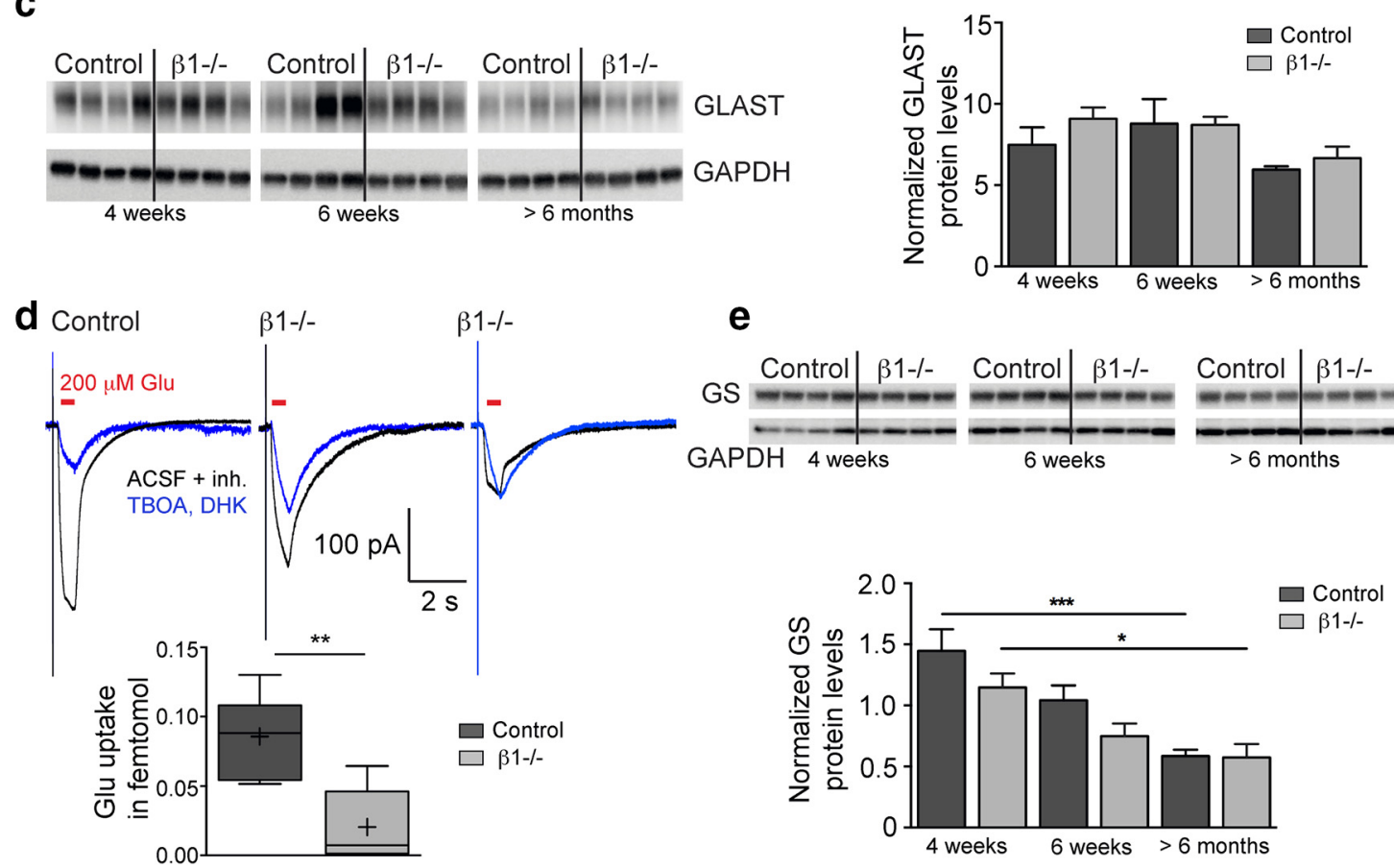

Figure 6. Glutamate uptake is impaired in mice with chronic astrogliosis. $\boldsymbol{a}$, Immunohistochemistry against the glutamate transporter Glt-1 and Western blot probing for Glt-1(b) and GLAST in the cortical gray matter of $\beta 1^{-/-}$(c) and control mice at different ages ( 4 and 6 weeks and $>6$ months). $\boldsymbol{d}$, Glutamate uptake was assessed after puff application of $200 \mu \mathrm{m}$ glutamate for $500 \mathrm{~ms}$ before and after the application of the glutamate transporter inhibitors TBOA and DHK. ACSF contained the inhibitors (inh.) TTX, AP-5, bicuculline, and CdCl. TBOA/DHK-sensitive glutamate uptake was reduced in $\beta 1^{-1-}$ astrocytes when compared with littermate controls. Whiskers in box-and-whisker plot show minimum to maximum values. The line in the middle of the box is plotted at the median, + indicates the mean.e, Protein expression levels of the astrocytic enzyme glutamine synthetase was unchanged in the cortical gray matter of $\beta 1^{-1-}$ and control mice at 4 and 6 weeks of age, but reduced in both genotypes in mice older than 6 months. Error bars in bar graphs refer to SEM. Statistical significance with ${ }^{*} p<0.05,{ }^{* *} p<0.01$, and ${ }^{* * *} p<0.001$.

matter ( $n=4$ for each genotype and age group). We found that levels of KCC2 and NKCC1 protein and the ratio between KCC2 and NKCC1 were unchanged at 4 weeks (Fig. $7 a-d$ ). At 6 weeks, KCC2 levels remained unchanged, whereas NKCC1 expression was significantly increased. In mice 6 months and older, KCC2 protein was significantly lower. In mice with chronic reactive astrogliosis, KCC2 to NKCC1 ratios are decreased after they are 6 weeks old (Fig. $7 a-d$ ).

NKCC1 is also expressed in astrocytes and endothelial cells (Pedersen et al., 2006; Macaulay and Zeuthen, 2012). Hence, we used immunohistochemistry to detect NKCC1 in animals 3 months of age. In controls, NKCC1 was expressed evenly throughout the cortical gray matter sparing only neuronal nuclei. We attempted to colocalize NKCC1 with fine astrocytic processes using Glt-1
(Fig. $6 a$ ) as a marker in confocal images. However, the resolution achieved by light microscopy was insufficient to unequivocally demonstrate an overlap between NKCC1 and Glt-1. Nevertheless, in $\beta 1^{-l-}$ mice, we found increased ring-like NKCC1 labeling within the cell soma of NeuN-labeled neurons (Fig. 7e). We did not observe increased levels of NKCC1 in astrocyte cell bodies or the main processes after labeling with GFAP (Fig. 7e).

Immunohistochemistry of the neuron-specific KCC2 revealed expression of this transporter at the periphery of the soma and within processes as previously reported (Campbell et al., 2015). In $\beta 1^{-1-}$ animals the KCC2 expression pattern was changed showing a more diffuse labeling not just at the periphery but also within neuronal soma (Fig. $7 f$ ). 
a

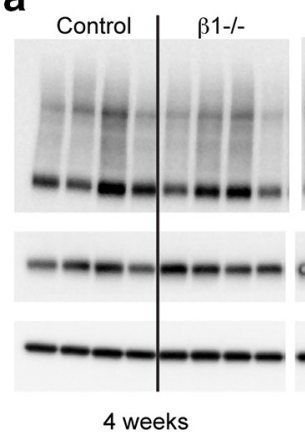

C

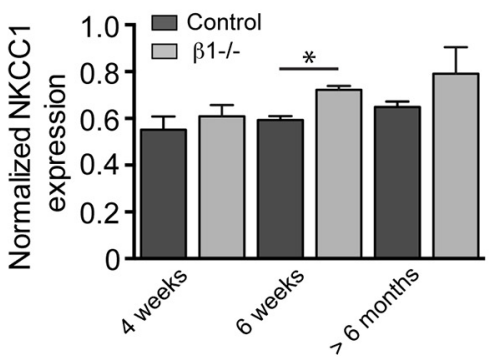

e Control

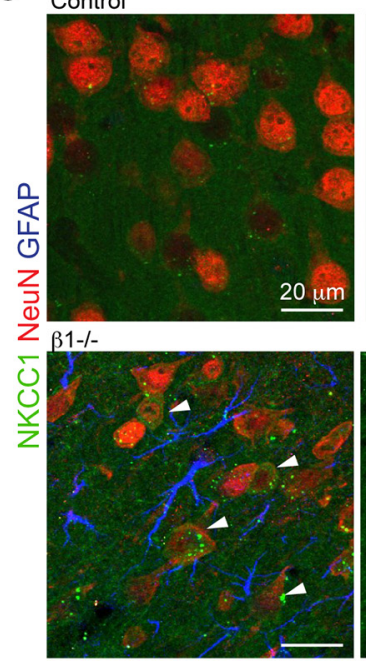

6 weeks

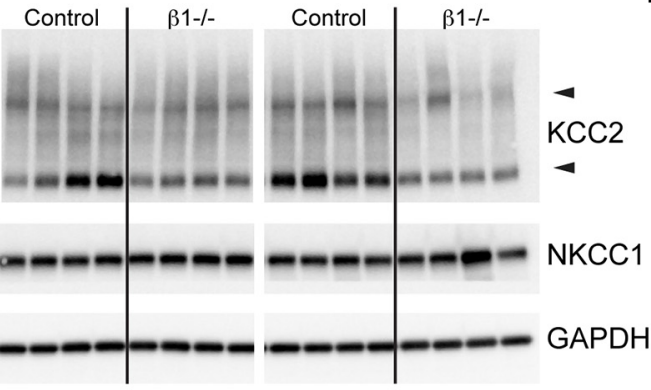

$>6$ months

d
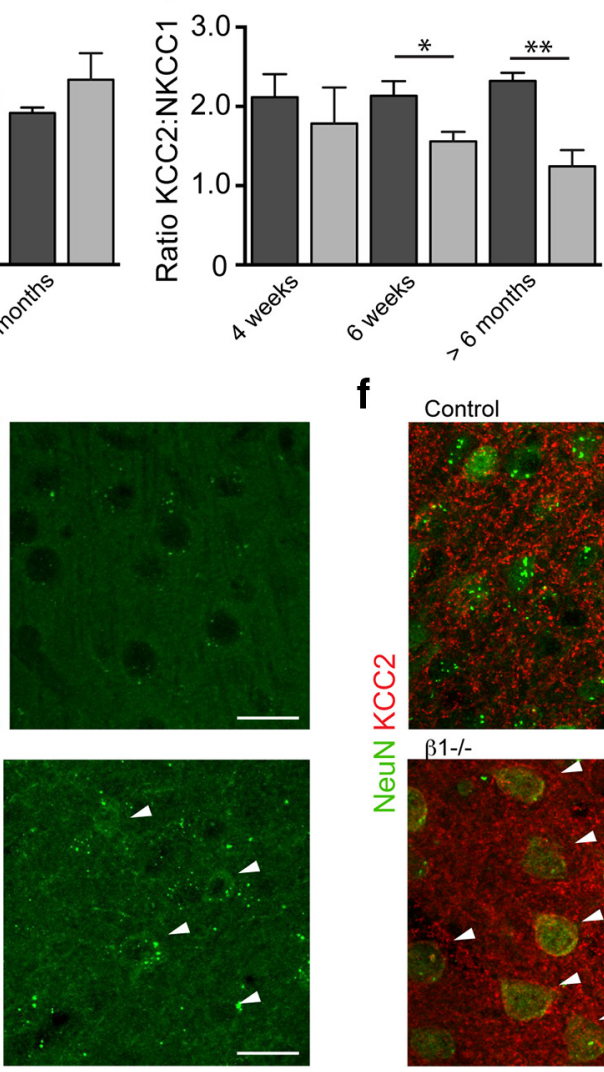

b

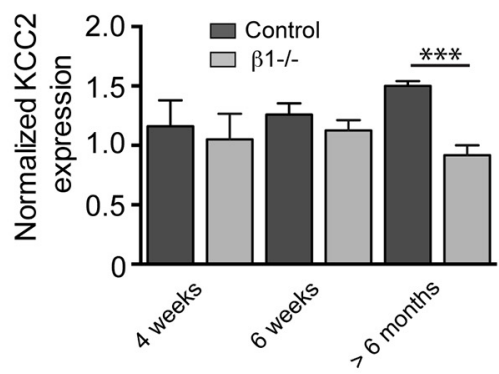

f

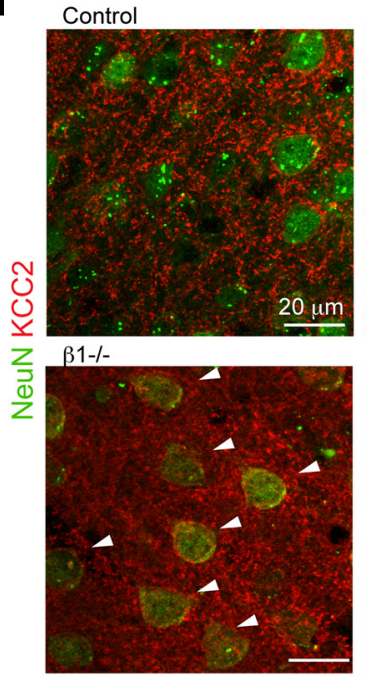

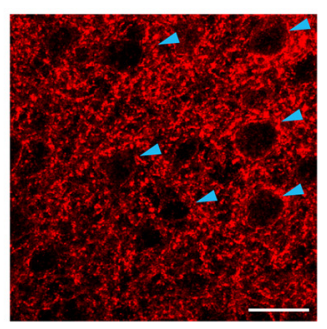

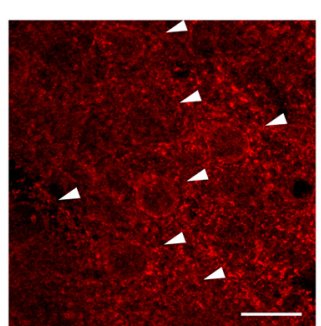

Figure 7. Bumetanide treatment rescues the seizure phenotype in a subset of mice with chronic astrogliosis. $\boldsymbol{a}$, Western blot analysis of the potassium-chloride cotransporter (KCC2) and the sodium potassium-chloride cotransporter (NKCC1). $\boldsymbol{b}$, Quantification of KCC2. $\boldsymbol{c}$, NKCC1 expression levels after normalization to the loading control GAPDH. $\boldsymbol{d}, \beta 1^{-1-}$ mice present with an upset ratio of the chloride transporters KCC 2 and NKCC 1 at 6 weeks and $>6$ months of age. Immunohistochemistry for NKCC $(e)$ and KCC2 $(f)$ in $\beta 1^{-/-}$and control cortical gray matter at 3 months of age. White arrow heads point at neurons with changed NKCC 1 or KCC2 expression patterns. Blue arrow heads point at normal, ring-like expression of KCC2 along the periphery of neuronal cell bodies. Error bars refer to SEM. Statistical significance with ${ }^{*} p<0.05,{ }^{* *} p<0.01$, and ${ }^{* * *} p<0.001$.

Together, these data indicate that neuronal NKCC1 and KCC2 protein distribution and levels changed in $\beta 1^{-1-}$ mice and that their neurons have adopted an immature phenotype.

Can bumetanide treatment reverse the seizure phenotype? To study whether the increased expression of NKCC1 relative to KCC2 in neurons is responsible for seizure activity (Kahle et al., 2008), we blocked NKCC1 in vivo with the diuretic drug bumetanide in $\beta 1^{-1-}$ and control mice (Fig. 8a,b). We recorded EEGs from 6- to 8-week-old mice, starting with a $48-72 \mathrm{~h}$ baseline before treatment with a very low dose of bumetanide (Rangroo Thrane et al., 2013; $5 \mathrm{mg} / \mathrm{kg}$, i.p., twice daily). We found that seizures were eliminated in a subset of $\beta 1^{-1-}$ animals (5/9), but the remaining animals did not respond (4/9; Fig. $8 a)$. GFAP levels determined by immunohistochemistry after com- pletion of the EEG recordings did not differ between treated and untreated animals (untreated $\beta 1^{-1-}: 219,416 \pm 51,461 n=9$; bumetanide-treated: $152,292 \pm 66,867, n=7$, two-tailed MannWhitney, $p=0.46)$. We never observed seizures in control mice before or after bumetanide treatment.

\section{Discussion}

A new epilepsy animal model with spontaneous recurrent seizures

There is a strong association between epilepsy and astrogliosis in acute and chronic animal models, and in human epilepsy brain tissue (D'Ambrosio, 2004; Wetherington et al., 2008; Carmignoto and Haydon, 2012; Coulter and Eid, 2012). However, it has been difficult to study astrogliosis in epileptogenesis without con- 


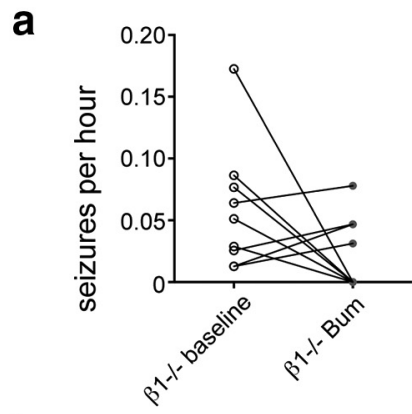

b

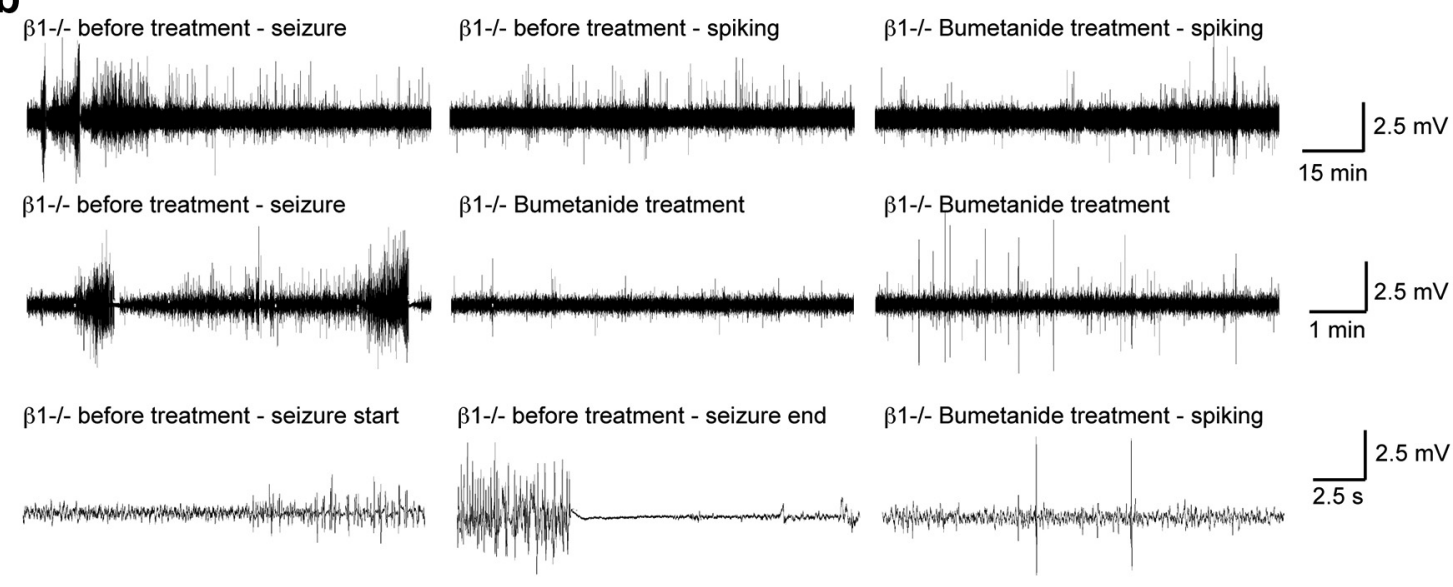

Figure 8. Bumetanide treatment reversed the seizure phenotype in a subset of mice with chronic astrogliosis. $\boldsymbol{a}$, The NKCC1 inhibitor bumetanide reversed the seizure phenotype in a subset of $\beta 1^{-/-}$mice, whereas another group of $\beta 1^{-/-}$mice did not respond. $\boldsymbol{b}$, EEG traces at different temporal resolution of a mouse (\#1615) before treatment and within $2 \mathrm{~h}$ after bumetanide treatment.

founding factors such as damage to the blood-brain barrier, inflammation, and pronounced cell death. Ortinski et al. (2010) reported hippocampal circuit hyperexcitability after induction of astrogliosis, and also noted a reduction in inhibitory, but not excitatory, synaptic currents. They found that the glutamateglutamine cycle failed, resulting in a downregulation of the astrocytic enzyme GS and insufficient GABA production. However, it is unknown whether astrogliosis and resulting hyperexcitability produced recurrent seizures in vivo.

In our study, we report that genetically induced chronic astrogliosis is sufficient to induce spontaneous, recurrent, generalized tonic-clonic seizures in vivo. We observed astrocytic cellular and functional changes believed to contribute to seizure development, such as impaired Kir4.1 function and decreased glutamate uptake in acute slices from these mice. In addition, we found indirect changes, such as mild microglial activation and a changed expression pattern of the cation-chloride cotransporters NKCC1 and KCC2 in cortical pyramidal neurons.

Epileptogenesis in the absence of blood-brain barrier defects Blood-brain barrier breach has been reported in epilepsy animal models and in epilepsy patients (Heinemann et al., 2012; Janigro, 2012). Serum factors are deposited in the brain parenchyma after blood-brain barrier breakdown and this alone can generate inflammation and astrogliosis and trigger seizures (Seiffert et al., 2004; Adams et al., 2007; Schachtrup et al., 2010; Heinemann et al., 2012; Janigro, 2012). One effect of albumin deposition is astrocytic TGFRII activation, which can then lead to downregulation of Kir4.1 and Glt- 1 through a TGF- $\beta$-mediated mechanism (Frigerio et al., 2012). It has been difficult to decipher whether these serum factors impact neuronal excitability directly or indirectly.

In our model, astrogliosis occurs in the absence of bloodbrain barrier damage (Robel et al., 2009), reflected by stable levels of Kir4.1 and Glt-1 proteins and mild microglial activation during seizure onset. This suggests that astrogliosis by itself is sufficient to induce epileptogenesis.

\section{Direct changes in reactive astrocytes contribute to epileptogenesis}

Astrocytes are essential for normal brain homeostasis. They maintain low concentrations of potassium and glutamate within the extracellular space and supply neurons with glutamine, a necessary precursor for glutamate and GABA synthesis. Yet in human epileptic hippocampi, glutamate levels have been found to be five times higher than in normal hippocampi (Coulter and Eid, 2012).

In $\beta 1^{-1-}$ mice with chronic astrogliosis, we found functional impairments in the Kir4.1 potassium channel and in glutamate transporters, but their protein levels were unchanged during seizure onset. Glutamate transporter trafficking, required for proper glutamate uptake, is crucially dependent on the cytoskeleton (Sullivan et al., 2007; Sheean et al., 2013). In reactive astrocytes, the cytoskeleton is markedly changed (Robel et al., 2011). Thus, glutamate uptake could be disrupted due to improper localization of the transporters despite normal total protein levels.

During development, immature, proliferating astrocytes do not yet express Kir4.1, and therefore have a depolarized RMP of approximately $-50 \mathrm{mV}$ (Ransom and Sontheimer, 1995; Bordey and Sontheimer, 1997). As the brain matures and astrocytic 
Kir4.1 expression levels increase (Nwaobi et al., 2014), astrocytes acquire their characteristic, very negative, RMP of approximately $-85 \mathrm{mV}$ (Olsen and Sontheimer, 2008). At the same time, protoplasmic cortical gray matter astrocytes downregulate typical proteins expressed in a dedifferentiated, immature state, such as GFAP (in mice), nestin, and vimentin or tenascin-C and 473HD, and exit the cell cycle. However, after adult brain injury, reactive astrocytes re-adopt an immature phenotype and can re-enter the cell cycle, coinciding with the loss of Kir4.1 and cell membrane depolarization (MacFarlane and Sontheimer, 2000; Higashimori and Sontheimer, 2007). Mice with chronic astrogliosis show upregulation of some of these markers, but do not re-enter the cell cycle (Robel et al., 2009). Accordingly, we did not observe Kir4.1 protein loss or membrane depolarization. Nonetheless, bariumsensitive Kir4.1-mediated potassium currents were reduced in mice with chronic astrogliosis. This alone may contribute to epileptogenesis since Kir4.1 conditional knock-out mice display stress-induced seizures (Djukic et al., 2007).

\section{Indirect effects of astrogliosis on the microenvironment \\ Neuronal chloride homeostasis}

In the adult CNS, GABA is the main inhibitory neurotransmitter that binds to the GABA A receptor. This chloride channel opens after ligand binding, facilitating passive flow of chloride ions either into or out of the cell according to the equilibrium potential (Kahle et al., 2008).

During development, GABA acts as an excitatory stimulus for immature neurons due to their high intracellular chloride concentration. GABA binds to its receptor, the channel opens, and chloride flows out of the immature cell to stimulate membrane depolarization. During postnatal development, neuronal intracellular chloride concentrations decrease in response to an expression switch of the CCC transporters, NKCC1 and KCC2. $\mathrm{NKCC1}$ is a sodium potassium chloride cotransporter that imports chloride into the cell, whereas KCC2 is a potassium chloride transporter that shunts chloride out of the cell. In the immature neuron, the KCC2 to NKCC1 ratio is low, resulting in high intracellular chloride, while in the mature neuron, NKCC1 levels are lower and KCC2 expression is higher, resulting in low intracellular chloride. Once GABA binds and the receptor opens, chloride flows into the cell and hyperpolarizes the membrane (Kahle et al., 2008). Although a regulation of the KCC2 and NKCC1 transporters by protein phosphorylation has been demonstrated (Kaila et al., 2014), the signaling mechanisms that govern this developmental switch and hence the conversion of GABA from excitatory to inhibitory transmitter remain largely elusive.

However, excitatory GABAergic signaling caused by perturbed neuronal chloride transport has been previously observed in brain slices from temporal lobe epilepsy patients (Cohen et al., 2002). Since NKCC1 is also involved in cell volume regulation, this transporter is regularly induced after CNS injury (Cohen et al., 2002). For example, increased NKCC1 activity or expression has been reported following cerebral hypoxic-ischemic injury (Kahle et al., 2008), traumatic brain injury (Lu et al., 2008), and pilocarpine-induced status epilepticus (Brandt et al., 2010). During a seizure, glutamate receptor activation and high extracellular potassium activate NKCC1 via serine-threonine phosphorylation, possibly perpetuating abnormally high intracellular chloride levels in mature neurons (Kahle et al., 2008). Simultaneously, KCC2 can be downregulated or functionally impaired after CNS injury, either by microglia-mediated BDNF release (Ferrini et al., 2013), or enhanced extracellular glutamate (Lee et al., 2011; Kahle et al., 2013), further shifting the KCC2 and NKCC1 ratio. This ratio appears to be unaltered in 4-week-old $\beta 1^{-/-}$mice, but is shifted in older animals, indicating that KCC2 protein downregulation and NKCC1 protein upregulation is secondary to astrogliosis. How gliosis induces changes in expression and localization of these transporters remains to be elucidated. Hence, the shift in NKCC1:KCC2 ratios are likely a consequence of seizures as previously suggested (Brandt et al., 2010) further perpetuating the phenotype. In a subset of mice, treatment with the NKCC1 inhibitor drug bumetanide alleviated the seizures.

NKCC1 is primarily a neuronal transporter although it is expressed in astrocytes as well. Here it has been suggested to contribute to $\mathrm{K}^{+}$uptake and water uptake, which may affect the size of the extracellular space. In astrocytes, NKCC1 activation is associated with elevated extracellular potassium concentrations, which can be associated with cellular swelling as a result of the cotransport of water (Macaulay and Zeuthen, 2012). A recent study clarified that NKCC1 did not contribute to potassium clearance or extracellular space shrinkage after stimulation of neuronal activity in hippocampal slices under physiological conditions (Larsen et al., 2014). Under pathological conditions, NKCC1 may contribute to astrocytic hypertrophy and edema (Rose and Karus, 2013). Thus, inhibiting NKCC1 in astrocytes might have beneficial effects, but so far positive effects of NKCC1 inhibition have largely been attributed to a reduction in edema formation (Chen and Sun, 2005; Kahle et al., 2009; Rose and Karus, 2013).

In our studies, we do not observe edema formation in $\beta 1^{-/-}$ animals. While bumetanide might also affect astrocytic NKCC1, the here observed anti-seizure effect is most likely due to an inhibition of neuronal $\mathrm{Cl}^{-}$accumulation.

\section{Microglia activation-epilepsy and inflammation}

Reactive astrocytes release cytokines that may induce changes in their cell biology, gene, and protein expression (Sofroniew, 2009; Sofroniew and Vinters, 2010; Devinsky et al., 2013). Cytokine release also activates microglia, which stimulates more cytokine release from these cells, possibly inducing a feedback loop between astrocytes and microglia (Liu et al., 2011). Indeed, we observed a low degree of microglia activation secondary to astrogliosis in 6 -week-old $\beta 1^{-/-}$mice. This activation was very mild, with little Cd11b upregulation, morphological change, or significant proliferation when compared with an acute injury (Robel et al., 2009). However, in $\beta 1^{-l-}$ mice, activated microglia might signal back to astrocytes and reinforce astrogliosis.

This back and forth signaling may explain why astrogliosis and microgliosis become more severe as the animals age. We did not observe an age-dependent increase in seizure frequency in $\beta 1^{-/-}$mice, but interictal spiking increased dramatically in mice older than 6 months. Given the relatively low numbers of seizures during the recording period, computed seizure frequencies might not be accurate enough to detect an age-dependent difference in seizure frequency. Generally, astrocytic and neuronal factors involved in the maintenance of balanced excitation and inhibition changed in older mice. Repeated seizures might contribute to enhanced inflammation at these later stages and this might perpetuate the seizure phenotype as reported for mesial temporal lobe epilepsy and epileptic encephalopathy (Avanzini et al., 2013).

In summary, we present a mouse model of chronic astrogliosis in which animals develop spontaneous tonic-clonic seizures in vivo generated by neuronal hyperexcitability. We identified two mechanisms that likely contribute to interictal spiking and seizures. First, impaired astrocytic glutamate uptake could drive hyperexcitability through the resulting increase in extracellular 
glutamate. Second, the reversed ratio of neuronal chloride transporters KCC2 and NKCC1 may disrupt the delicate balance of excitation and inhibition in these mice.

These data support the hypothesis that reactive astrogliosis is sufficient to induce epileptic seizures.

\section{References}

Adams RA, Schachtrup C, Davalos D, Tsigelny I, Akassoglou K (2007) Fibrinogen signal transduction as a mediator and therapeutic target in inflammation: lessons from multiple sclerosis. Curr Med Chem 14:2925-2936. CrossRef Medline

Avanzini G, Depaulis A, Tassinari A, de Curtis M (2013) Do seizures and epileptic activity worsen epilepsy and deteriorate cognitive function? Epilepsia 54 [Suppl 8]:14-21. CrossRef Medline

Ben-Ari Y, Khalilov I, Kahle KT, Cherubini E (2012) The GABA excitatory/ inhibitory shift in brain maturation and neurological disorders. Neuroscientist 18:467-486. CrossRef Medline

Bordey A, Sontheimer H (1997) Postnatal development of ionic currents in rat hippocampal astrocytes in situ. J Neurophysiol 78:461-477. Medline

Bordey A, Sontheimer H (1998) Properties of human glial cells associated with epileptic seizure foci. Epilepsy Res 32:286-303. CrossRef Medline

Bordey A, Lyons SA, Hablitz JJ, Sontheimer H (2001) Electrophysiological characteristics of reactive astrocytes in experimental cortical dysplasia. J Neurophysiol 85:1719-1731. Medline

Brandt C, Nozadze M, Heuchert N, Rattka M, Löscher W (2010) Diseasemodifying effects of phenobarbital and the NKCC1 inhibitor bumetanide in the pilocarpine model of temporal lobe epilepsy. J Neurosci 30:86028612. CrossRef Medline

Buckingham SC, Campbell SL, Haas BR, Montana V, Robel S, Ogunrinu T, Sontheimer H (2011) Glutamate release by primary brain tumors induces epileptic activity. Nat Med 17:1269-1274. CrossRef Medline

Cahoy JD, Emery B, Kaushal A, Foo LC, Zamanian JL, Christopherson KS, Xing Y, Lubischer JL, Krieg PA, Krupenko SA, Thompson WJ, Barres BA (2008) A transcriptome database for astrocytes, neurons, and oligodendrocytes: a new resource for understanding brain development and function. J Neurosci 28:264-278. CrossRef Medline

Campbell SL, Robel S, Cuddapah VA, Robert S, Buckingham SC, Kahle KT, Sontheimer H (2015) GABAergic disinhibition and impaired KCC2 cotransporter activity underlie tumor-associated epilepsy. Glia 63:23-36. CrossRef Medline

Carmignoto G, Haydon PG (2012) Astrocyte calcium signaling and epilepsy. Glia 60:1227-1233. CrossRef Medline

Chen H, Sun D (2005) The role of Na-K-Cl co-transporter in cerebral ischemia. Neurol Res 27:280-286. CrossRef Medline

Cohen I, Navarro V, Clemenceau S, Baulac M, Miles R (2002) On the origin of interictal activity in human temporal lobe epilepsy in vitro. Science 298:1418-1421. CrossRef Medline

Coulter DA, Eid T (2012) Astrocytic regulation of glutamate homeostasis in epilepsy. Glia 60:1215-1226. CrossRef Medline

D'Ambrosio R (2004) The role of glial membrane ion channels in seizures and epileptogenesis. Pharmacol Ther 103:95-108. CrossRef Medline

Devinsky O, Vezzani A, Najjar S, De Lanerolle NC, Rogawski MA (2013) Glia and epilepsy: excitability and inflammation. Trends Neurosci 36: 174-184. CrossRef Medline

Djukic B, Casper KB, Philpot BD, Chin LS, McCarthy KD (2007) Conditional knock-out of Kir4.1 leads to glial membrane depolarization, inhibition of potassium and glutamate uptake, and enhanced short-term synaptic potentiation. J Neurosci 27:11354-11365. CrossRef Medline

Ferrini F, Trang T, Mattioli TA, Laffray S, Del'Guidice T, Lorenzo LE, Castonguay A, Doyon N, Zhang W, Godin AG, Mohr D, Beggs S, Vandal K, Beaulieu JM, Cahill CM, Salter MW, De Koninck Y (2013) Morphine hyperalgesia gated through microglia-mediated disruption of neuronal $\mathrm{Cl}(-)$ homeostasis. Nat Neurosci 16:183-192. CrossRef Medline

Frigerio F, Frasca A, Weissberg I, Parrella S, Friedman A, Vezzani A, Noé FM (2012) Long-lasting pro-ictogenic effects induced in vivo by rat brain exposure to serum albumin in the absence of concomitant pathology. Epilepsia 53:1887-1897. CrossRef Medline

Goebbels S, Bormuth I, Bode U, Hermanson O, Schwab MH, Nave KA (2006) Genetic targeting of principal neurons in neocortex and hippocampus of NEX-Cre mice. Genesis 44:611-621. CrossRef Medline

Goldberg EM, Coulter DA (2013) Mechanisms of epileptogenesis: a conver- gence on neural circuit dysfunction. Nat Rev Neurosci 14:337-349. CrossRef Medline

Gutnick MJ, Connors BW, Prince DA (1982) Mechanisms of neocortical epileptogenesis in vitro. J Neurophysiol 48:1321-1335. Medline

Heinemann U, Kaufer D, Friedman A (2012) Blood-brain barrier dysfunction, TGFbeta signaling, and astrocyte dysfunction in epilepsy. Glia 60: 1251-1257. CrossRef Medline

Higashimori H, Sontheimer H (2007) Role of Kir4.1 channels in growth control of glia. Glia 55:1668-1679. CrossRef Medline

Holmseth S, Dehnes Y, Bjørnsen LP, Boulland JL, Furness DN, Bergles D, Danbolt NC (2005) Specificity of antibodies: unexpected crossreactivity of antibodies directed against the excitatory amino acid transporter 3 (EAAT3). Neuroscience 136:649-660. CrossRef Medline

Janigro D (2012) Are you in or out? Leukocyte, ion, and neurotransmitter permeability across the epileptic blood-brain barrier. Epilepsia 53 [Suppl 1]:26-34. CrossRef Medline

Jefferys JG (1990) Basic mechanisms of focal epilepsies. Exp Physiol 75:127162. CrossRef Medline

Kahle KT, Staley KJ, Nahed BV, Gamba G, Hebert SC, Lifton RP, Mount DB (2008) Roles of the cation-chloride cotransporters in neurological disease. Nat Clin Pract Neurol 4:490-503. CrossRef Medline

Kahle KT, Simard JM, Staley KJ, Nahed BV, Jones PS, Sun D (2009) Molecular mechanisms of ischemic cerebral edema: role of electroneutral ion transport. Physiology 24:257-265. CrossRef Medline

Kahle KT, Deeb TZ, Puskarjov M, Silayeva L, Liang B, Kaila K, Moss SJ (2013) Modulation of neuronal activity by phosphorylation of the K-Cl cotransporter KCC2. Trends Neurosci 36:726-737. CrossRef Medline

Kaila K, Price TJ, Payne JA, Puskarjov M, Voipio J (2014) Cation-chloride cotransporters in neuronal development, plasticity and disease. Nat Rev Neurosci 15:637-654. CrossRef Medline

Larsen BR, Assentoft M, Cotrina ML, Hua SZ, Nedergaard M, Kaila K, Voipio J, MacAulay N (2014) Contributions of the $\mathrm{Na}(+) / \mathrm{K}(+)$-ATPase, NKCC1, and Kir4.1 to hippocampal $\mathrm{K}(+)$ clearance and volume responses. Glia 62:608-622. CrossRef Medline

Lee HH, Deeb TZ, Walker JA, Davies PA, Moss SJ (2011) NMDA receptor activity downregulates KCC2 resulting in depolarizing GABAA receptormediated currents. Nat Neurosci 14:736-743. CrossRef Medline

Lehre KP, Levy LM, Ottersen OP, Storm-Mathisen J, Danbolt NC (1995) Differential expression of two glial glutamate transporters in the rat brain: quantitative and immunocytochemical observations. J Neurosci 15:18351853. Medline

Li Y, Zhou Y, Danbolt NC (2012) The rates of postmortem proteolysis of glutamate transporters differ dramatically between cells and between transporter subtypes. J Histochem Cytochem 60:811-821. CrossRef Medline

Liu W, Tang Y, Feng J (2011) Cross talk between activation of microglia and astrocytes in pathological conditions in the central nervous system. Life Sci 89:141-146. CrossRef Medline

Lu KT, Cheng NC, Wu CY, Yang YL (2008) NKCC1-mediated traumatic brain injury-induced brain edema and neuron death via Raf/MEK/MAPK cascade. Crit Care Med 36:917-922. CrossRef Medline

Macaulay N, Zeuthen T (2012) Glial K(+) clearance and cell swelling: key roles for cotransporters and pumps. Neurochem Res 37:2299-2309. CrossRef Medline

MacFarlane SN, Sontheimer H (2000) Changes in ion channel expression accompany cell cycle progression of spinal cord astrocytes. Glia 30:39-48. CrossRef Medline

Nwaobi SE, Lin E, Peramsetty SR, Olsen ML (2014) DNA methylation functions as a critical regulator of Kir4.1 expression during CNS development. Glia 62:411-427. CrossRef Medline

Olsen ML, Sontheimer H (2008) Functional implications for Kir4.1 channels in glial biology: from $\mathrm{K}+$ buffering to cell differentiation. J Neurochem 107:589-601. CrossRef Medline

Olsen ML, Higashimori H, Campbell SL, Hablitz JJ, Sontheimer H (2006) Functional expression of Kir4.1 channels in spinal cord astrocytes. Glia 53:516-528. CrossRef Medline

Olsen ML, Campbell SL, Sontheimer H (2007) Differential distribution of Kir4.1 in spinal cord astrocytes suggests regional differences in $\mathrm{K}+$ homeostasis. J Neurophysiol 98:786-793. CrossRef Medline

Ortinski PI, Dong J, Mungenast A, Yue C, Takano H, Watson DJ, Haydon PG, Coulter DA (2010) Selective induction of astrocytic gliosis generates 
deficits in neuronal inhibition. Nat Neurosci 13:584-591. CrossRef Medline

Pedersen SF, O’Donnell ME, Anderson SE, Cala PM (2006) Physiology and pathophysiology of $\mathrm{Na}+/ \mathrm{H}+$ exchange and $\mathrm{Na}+-\mathrm{K}+-2 \mathrm{Cl}^{-}$cotransport in the heart, brain, and blood. Am J Physiol Regul Integr Comp Physiol 291:R1-R25. CrossRef Medline

Pinto DJ, Patrick SL, Huang WC, Connors BW (2005) Initiation, propagation, and termination of epileptiform activity in rodent neocortex in vitro involve distinct mechanisms. J Neurosci 25:8131-8140. CrossRef Medline

Potocnik AJ, Brakebusch C, Fässler R (2000) Fetal and adult hematopoietic stem cells require betal integrin function for colonizing fetal liver, spleen, and bone marrow. Immunity 12:653-663. CrossRef Medline

Rangroo Thrane V, Thrane AS, Wang F, Cotrina ML, Smith NA, Chen M, Xu Q, Kang N, Fujita T, Nagelhus EA, Nedergaard M (2013) Ammonia triggers neuronal disinhibition and seizures by impairing astrocyte potassium buffering. Nat Med 19:1643-1648. CrossRef Medline

Ransom CB, Sontheimer H (1995) Biophysical and pharmacological characterization of inwardly rectifying $\mathrm{K}+$ currents in rat spinal cord astrocytes. J Neurophysiol 73:333-346. Medline

Robel S, Mori T, Zoubaa S, Schlegel J, Sirko S, Faissner A, Goebbels S, Dimou L, Götz M (2009) Conditional deletion of betal-integrin in astroglia causes partial reactive gliosis. Glia 57:1630-1647. CrossRef Medline

Robel S, Bardehle S, Lepier A, Brakebusch C, Götz M (2011) Genetic deletion of cdc42 reveals a crucial role for astrocyte recruitment to the injury site in vitro and in vivo. J Neurosci 31:12471-12482. CrossRef Medline

Rogawski MA (2013) AMPA receptors as a molecular target in epilepsy therapy. Acta Neurol Scand Suppl 9-18. CrossRef Medline

Rose CR, Karus C (2013) Two sides of the same coin: sodium homeostasis and signaling in astrocytes under physiological and pathophysiological conditions. Glia 61:1191-1205. CrossRef Medline

Schachtrup C, Ryu JK, Helmrick MJ, Vagena E, Galanakis DK, Degen JL, Margolis RU, Akassoglou K (2010) Fibrinogen triggers astrocyte scar formation by promoting the availability of active TGF-beta after vascular damage. J Neurosci 30:5843-5854. CrossRef Medline

Seifert G, Steinhäuser C (2011) Neuron-astrocyte signaling and epilepsy. Exp Neurol 244:4-10. CrossRef Medline

Seifert G, Carmignoto G, Steinhäuser C (2010) Astrocyte dysfunction in epilepsy. Brain Res Rev 63:212-221. CrossRef Medline
Seiffert E, Dreier JP, Ivens S, Bechmann I, Tomkins O, Heinemann U, Friedman A (2004) Lasting blood-brain barrier disruption induces epileptic focus in the rat somatosensory cortex. J Neurosci 24:7829-7836. CrossRef Medline

Sheean RK, Lau CL, Shin YS, O'Shea RD, Beart PM (2013) Links between l-glutamate transporters, $\mathrm{Na}(+) / \mathrm{K}(+)$-ATPase and cytoskeleton in astrocytes: evidence following inhibition with rottlerin. Neuroscience 254: 335-346. CrossRef Medline

Sofroniew MV (2009) Molecular dissection of reactive astrogliosis and glial scar formation. Trends Neurosci 32:638-647. CrossRef Medline

Sofroniew MV, Vinters HV (2010) Astrocytes: biology and pathology. Acta Neuropathol 119:7-35. CrossRef Medline

Sullivan SM, Lee A, Björkman ST, Miller SM, Sullivan RK, Poronnik P, Colditz PB, Pow DV (2007) Cytoskeletal anchoring of GLAST determines susceptibility to brain damage: an identified role for GFAP. J Biol Chem 282:29414-29423. CrossRef Medline

Thurman DJ, Beghi E, Begley CE, Berg AT, Buchhalter JR, Ding D, Hesdorffer DC, Hauser WA, Kazis L, Kobau R, Kroner B, Labiner D, Liow K, Logroscino G, Medina MT, Newton CR, Parko K, Paschal A, Preux PM, Sander JW, et al. (2011) Standards for epidemiologic studies and surveillance of epilepsy. Epilepsia 52 [Suppl 7]:2-26. CrossRef Medline

Trevelyan AJ, Sussillo D, Watson BO, Yuste R (2006) Modular propagation of epileptiform activity: evidence for an inhibitory veto in neocortex. J Neurosci 26:12447-12455. CrossRef Medline

Verkhratsky A, Sofroniew MV, Messing A, deLanerolle NC, Rempe D, Rodríguez JJ, Nedergaard M (2012) Neurological diseases as primary gliopathies: a reassessment of neurocentrism. ASN Neuro 4:e00082. CrossRef Medline

Volterra A, Meldolesi J (2005) Astrocytes, from brain glue to communication elements: the revolution continues. Nat Rev Neurosci 6:626-640. CrossRef Medline

Wahab A, Albus K, Gabriel S, Heinemann U (2010) In search of models of pharmacoresistant epilepsy. Epilepsia 51 [Suppl 3]:154-159. CrossRef Medline

Wetherington J, Serrano G, Dingledine R (2008) Astrocytes in the epileptic brain. Neuron 58:168-178. CrossRef Medline

Zhuo L, Theis M, Alvarez-Maya I, Brenner M, Willecke K, Messing A (2001) hGFAP-cre transgenic mice for manipulation of glial and neuronal function in vivo. Genesis 31:85-94. CrossRef Medline 